9.

\author{
إستهداف الثباب بالخدمة الإرشادية الزراعية بمحافظة الوادي الجديد

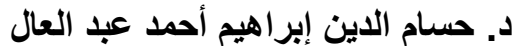

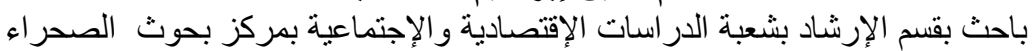

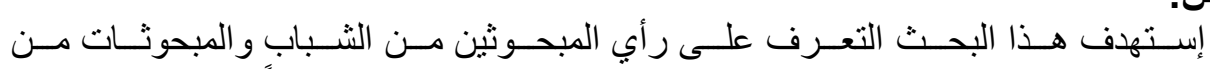

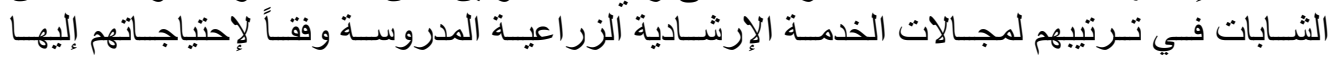

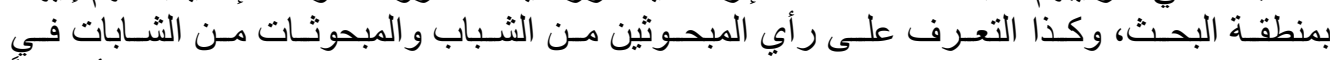

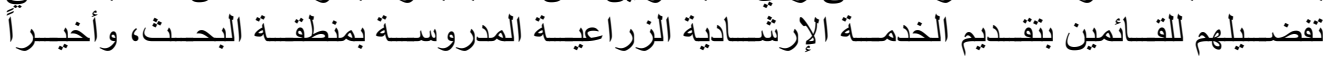

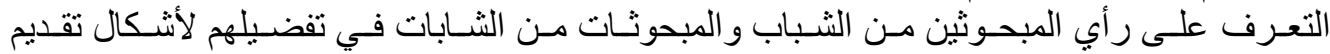

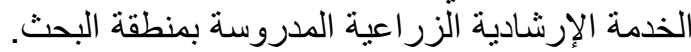

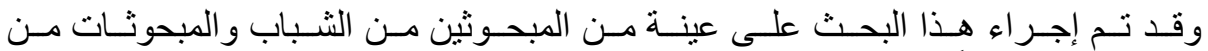

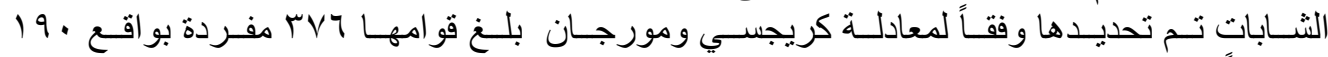

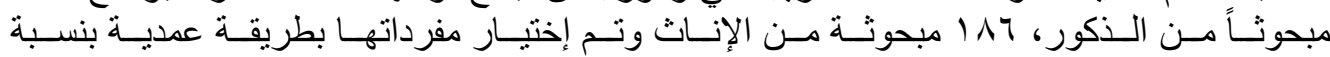

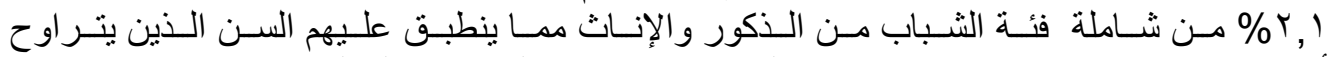

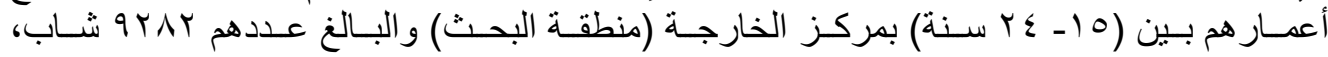

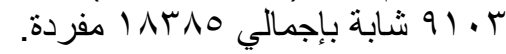

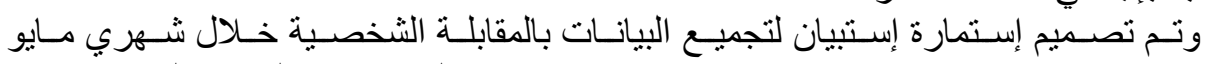

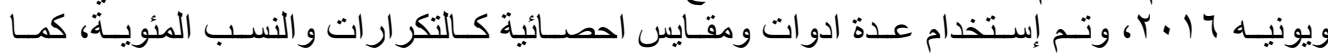

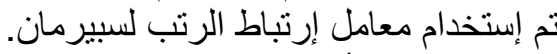

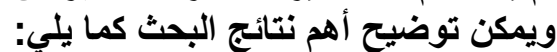

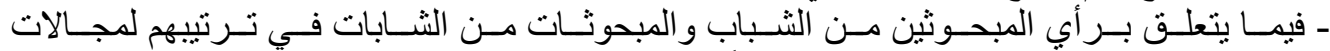

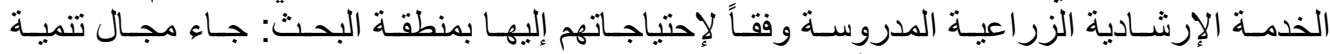

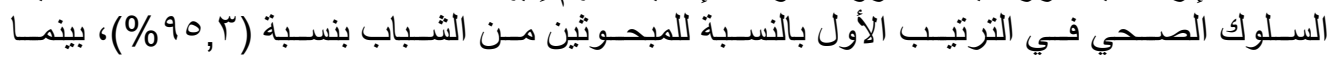

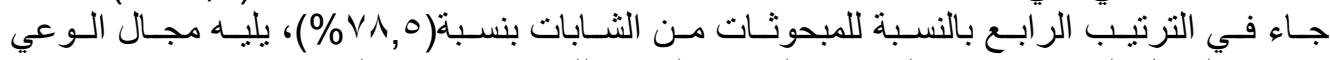

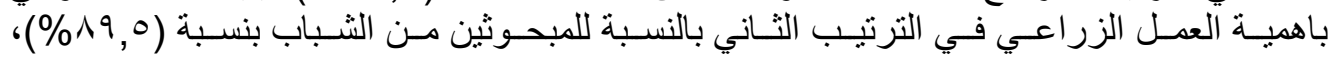

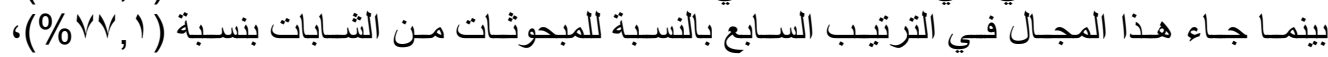

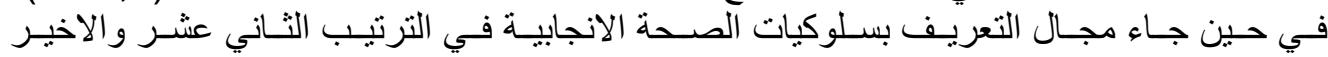

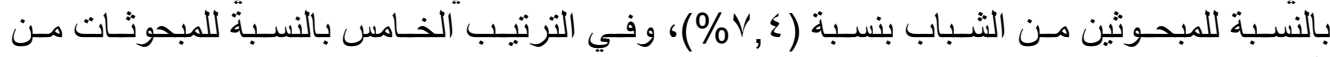

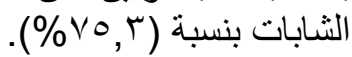

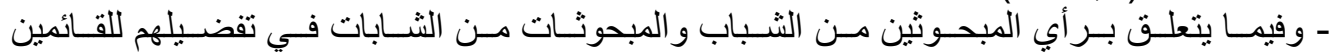

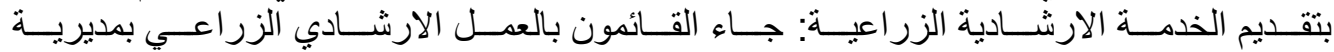

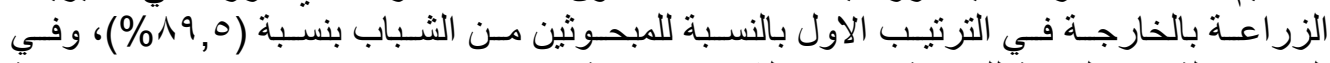

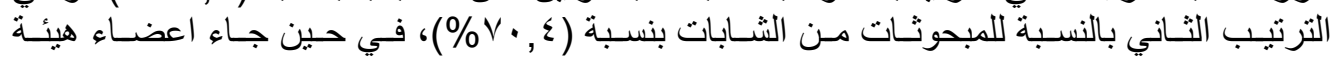

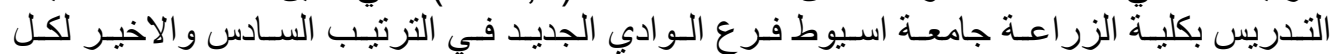
من الثباب و الثـابات بمنطقة البحث. الثئ.

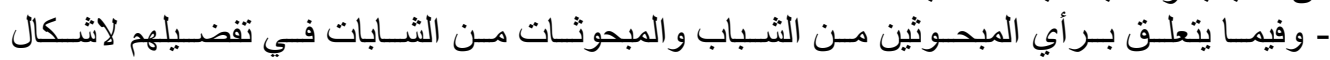

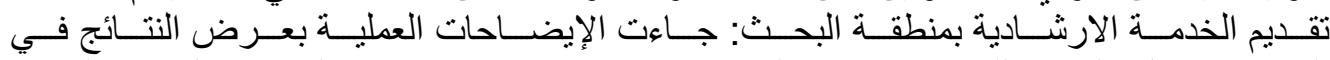

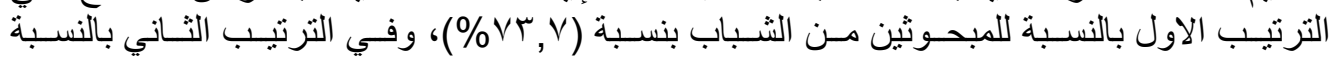

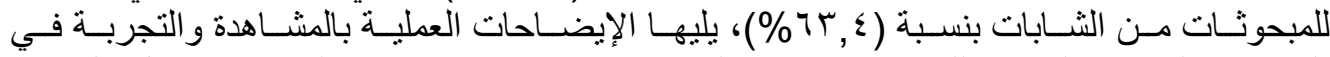

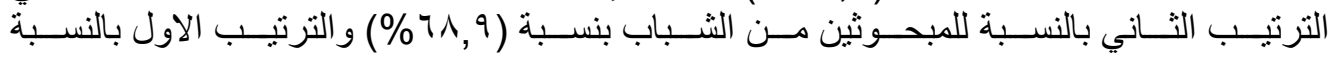

Fayoum J. Agric. Res. \& Dev., Vol. 30, No.2, July, 2016 
91

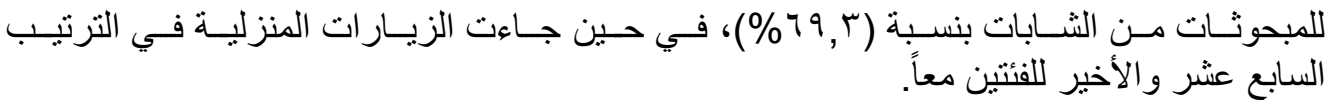

المقدمة والمشكلة البحثية الاخير

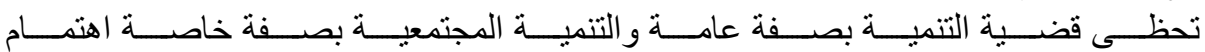

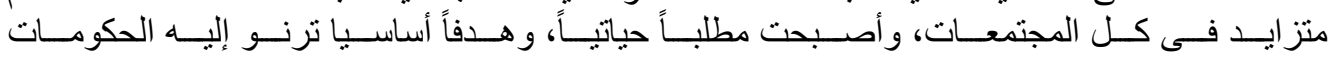

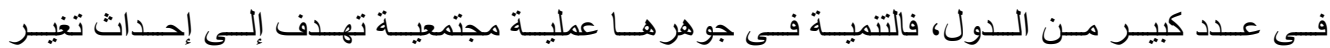

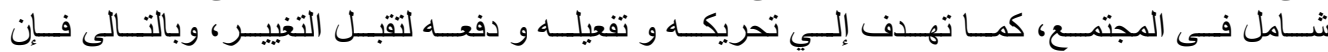

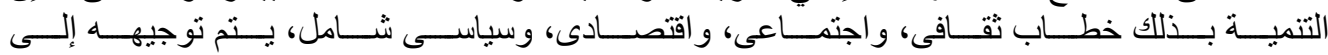

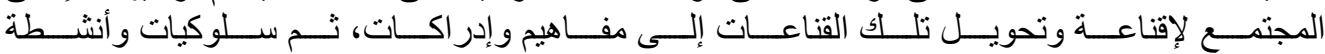

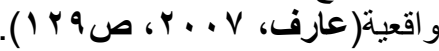

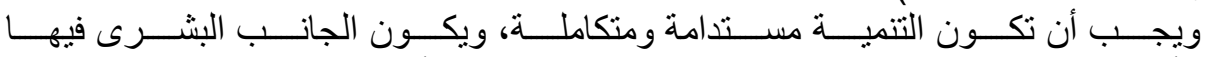

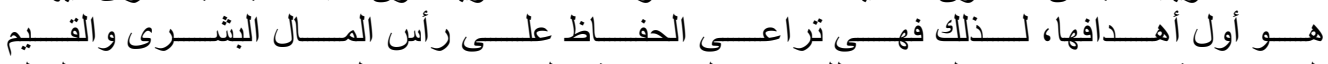

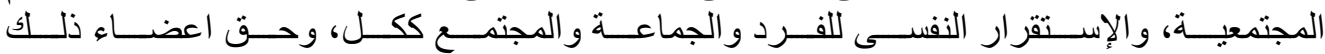

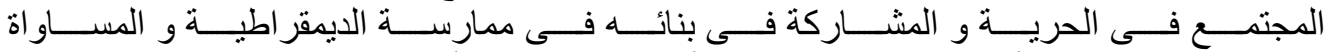

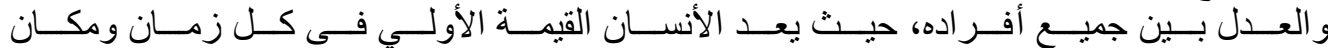

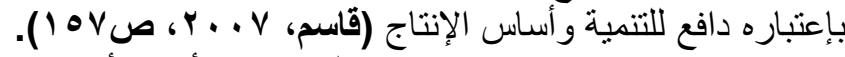

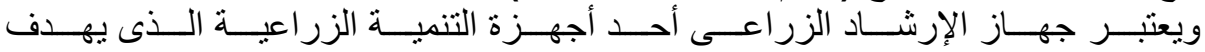

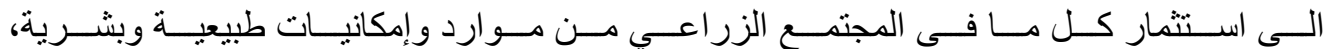

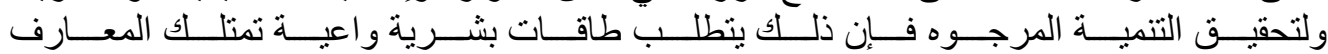

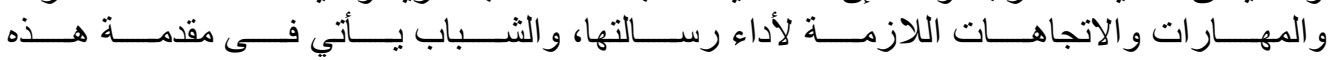

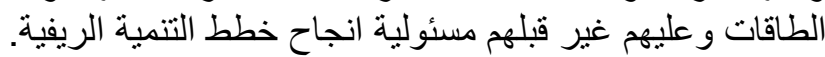

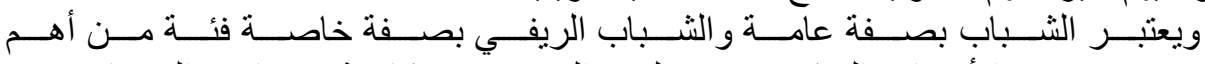

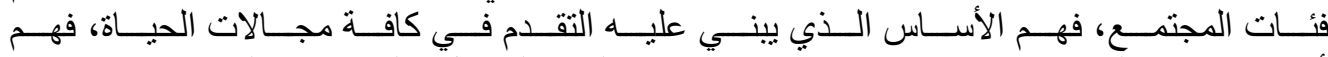

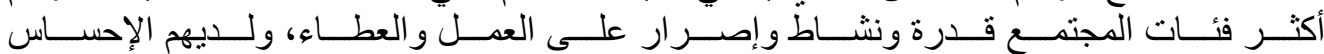

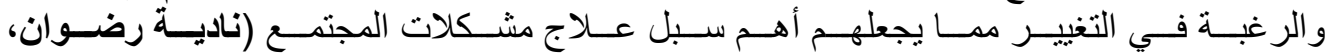

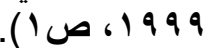

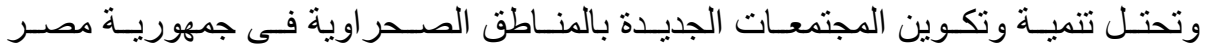

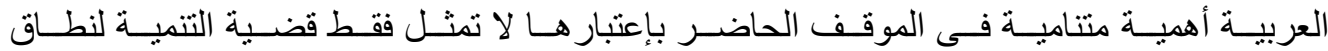

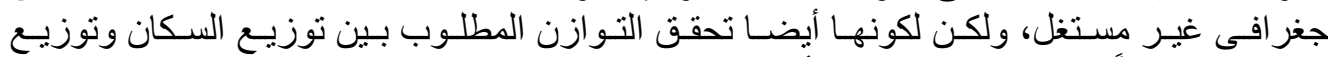

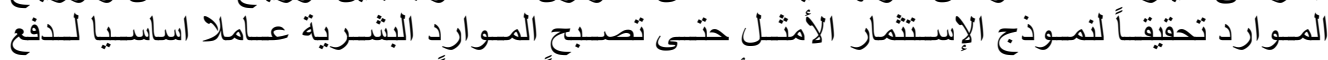

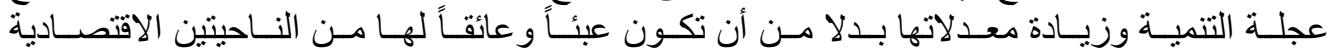

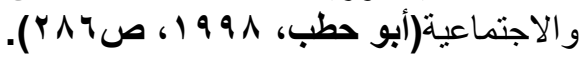

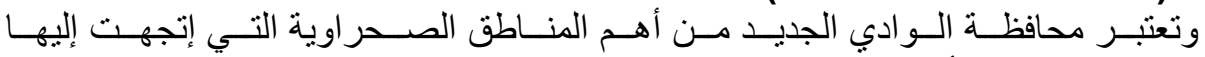

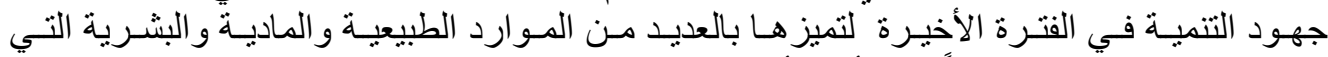

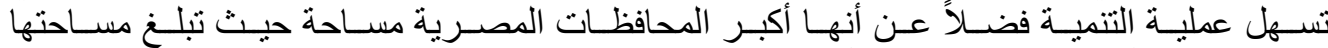

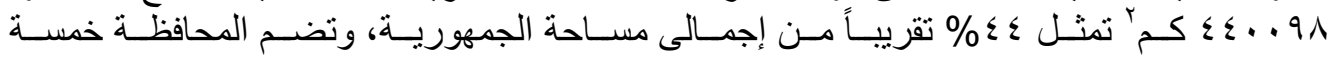

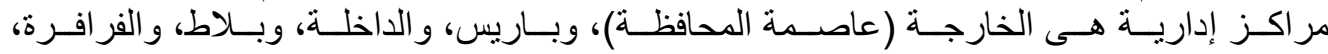

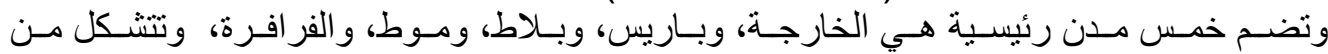

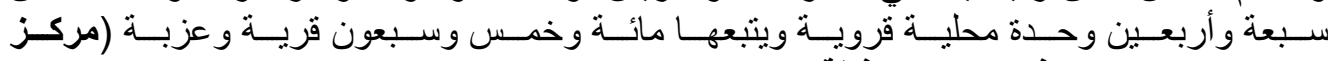

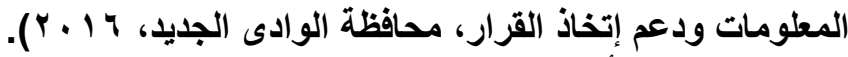

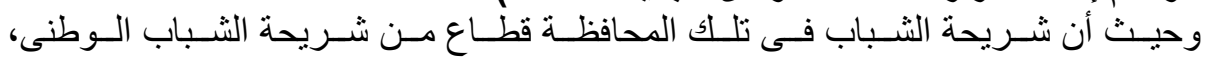

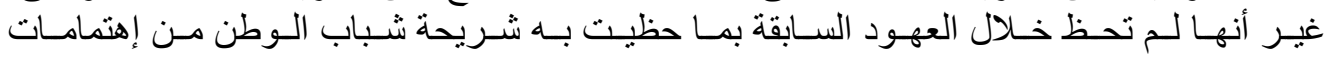

Fayoum J. Agric. Res. \& Dev., Vol. 30, No.2, July, 2016 
qr

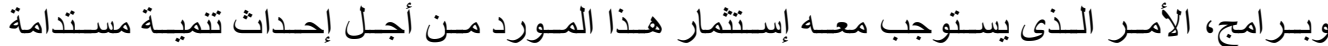

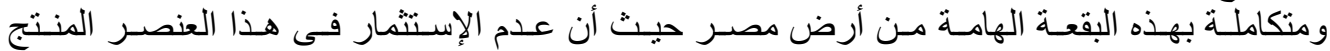

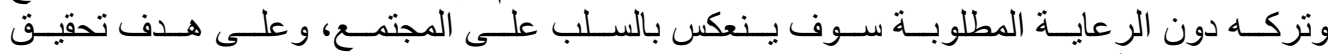

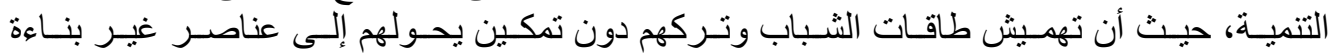
للتنمية فى الحاضر و المستقبل.

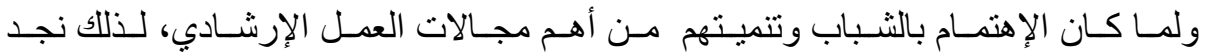

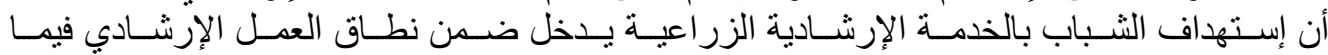

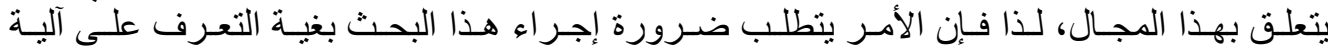

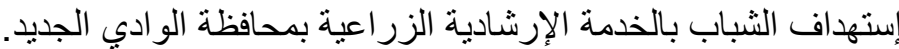

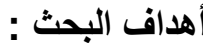

من خلال العرض البحث : العـابق فقد تحددث أهداف البحث فيما يلي:

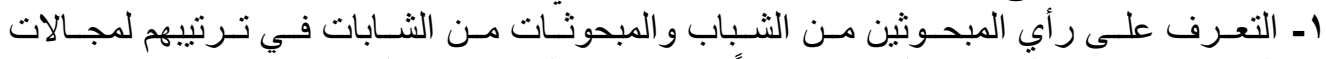

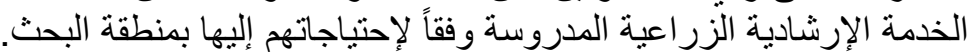

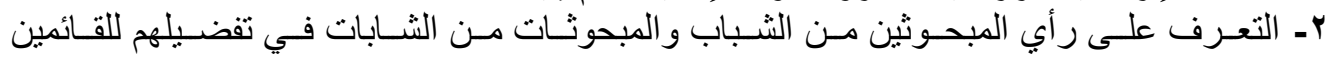

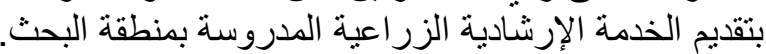

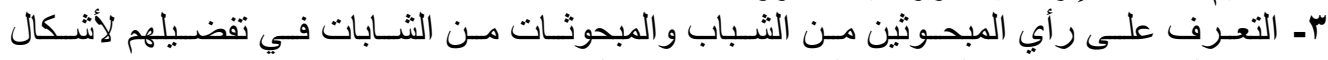
تقديم الخدمة الإرشادية الزراعية المدروسة بمنطقة البحث.

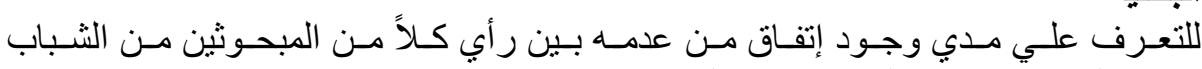

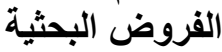
و المبحوثات من الثابات بمنطقة البحث فيما يتعلق بـ:

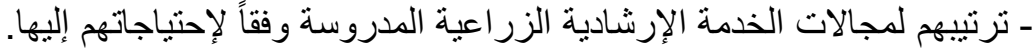

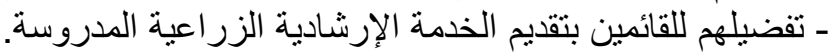

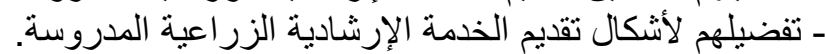

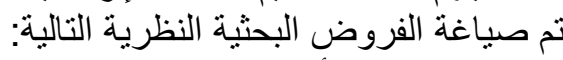

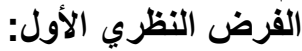

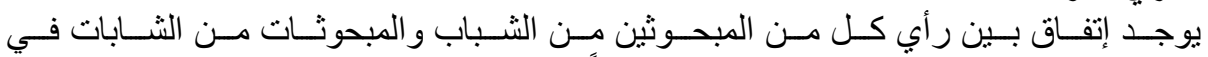

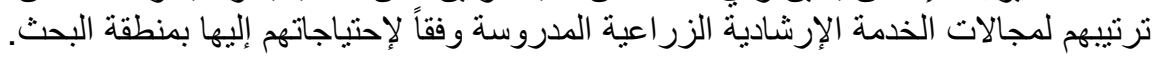

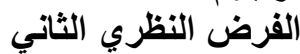
يوجد إتفاق بين رأي كل من المبحوثين من الثباب و المبحوثات من الثنابات في تفضيلهر

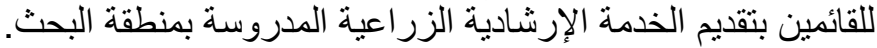

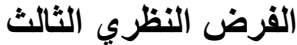
يوجد إتفاق بين رأي كل من المبحوثين من الثباب و المبحوثات من الثنابات في تفضيلهم

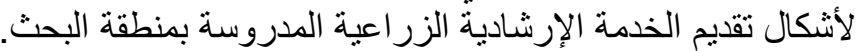

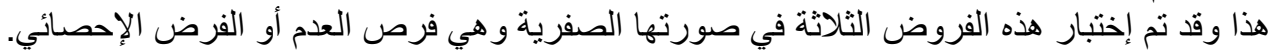

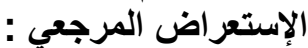

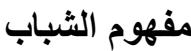

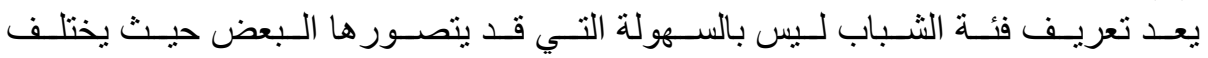

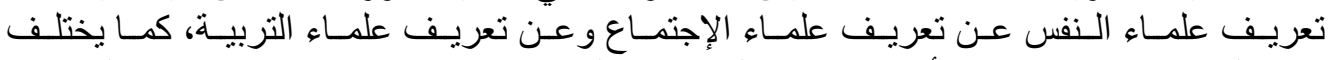

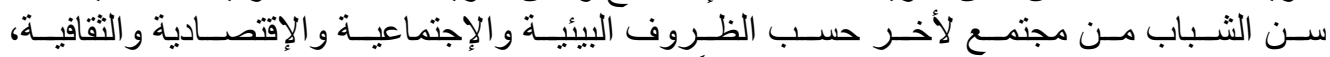

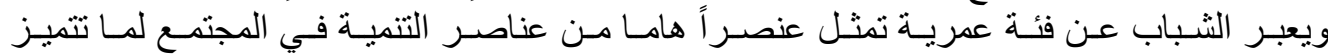

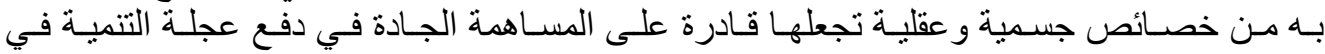

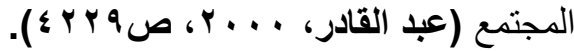

Fayoum J. Agric. Res. \& Dev., Vol. 30, No.2, July, 2016 
94

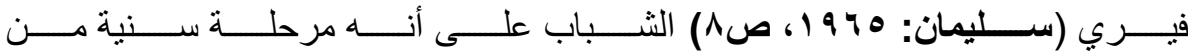

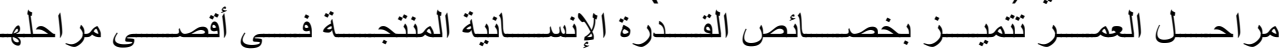

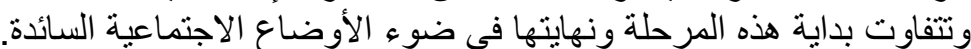

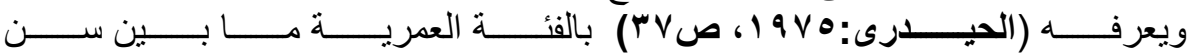

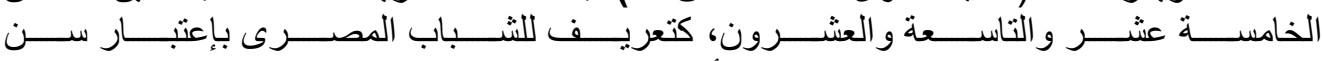

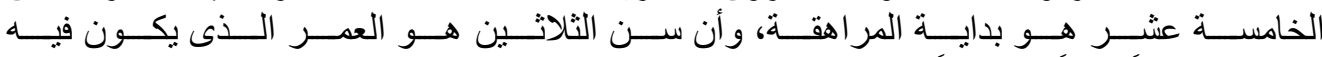

الإنسان ناضجاً عقلياً ووجدانياً.

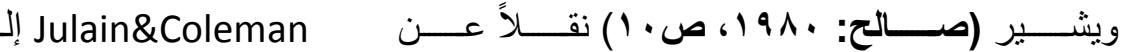

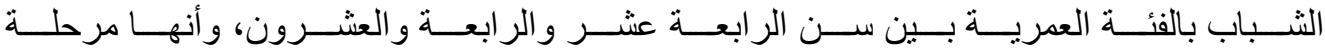
تحول من الطفولة إلى مرحلة الكبار.

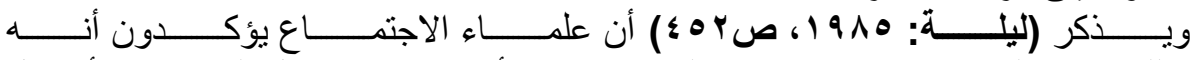

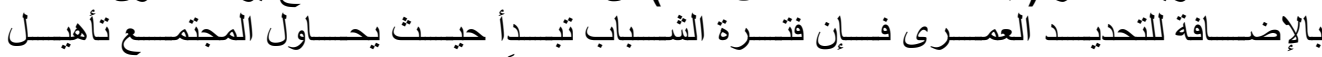

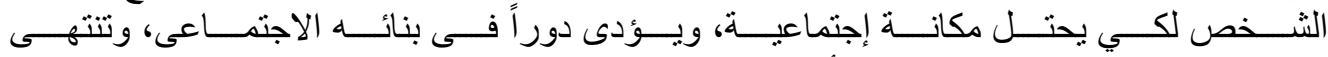

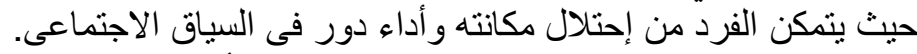

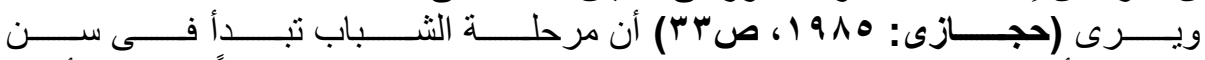

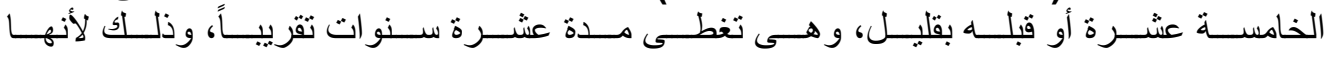

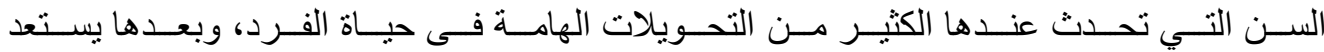

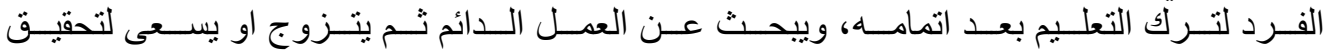

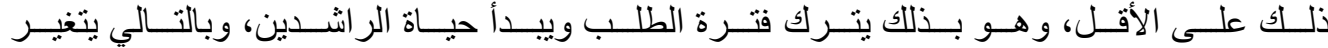
تصويره لذاته ولأخرين وللمجتمع.

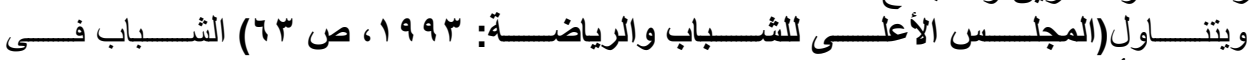

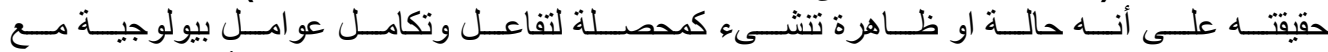

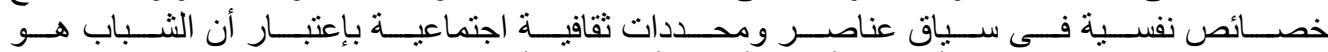
أقصى درجات الحيوية بيولوجياً وفيزيقياً و عقلياً ونفسياً واجتماعياً.

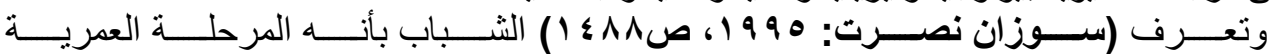

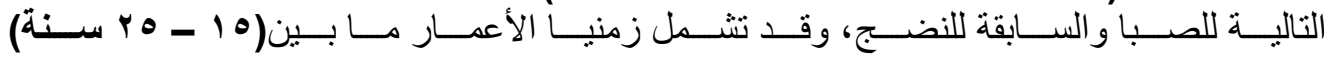

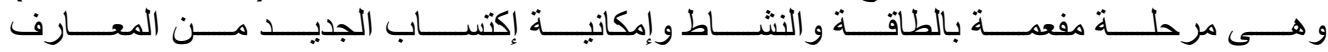

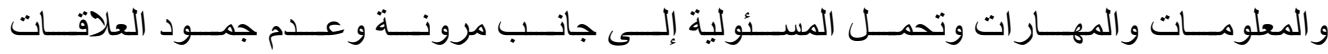
الإنسانية.

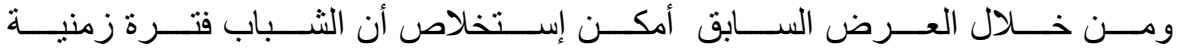

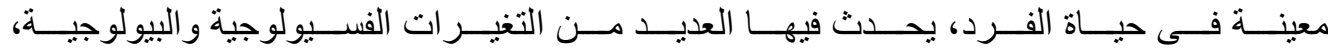

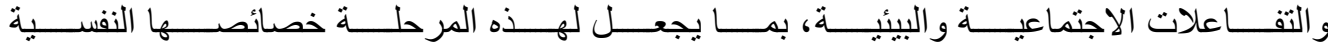

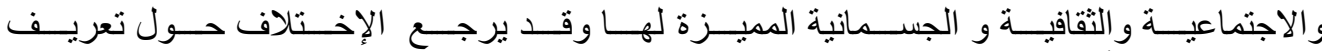
الشباب إلى عدة أسباب منها: ا - إختلاف الأهداف المنشودة في وضع التعريف، وتباين المفاهيم والأفكار العامة التي يقوم عليها

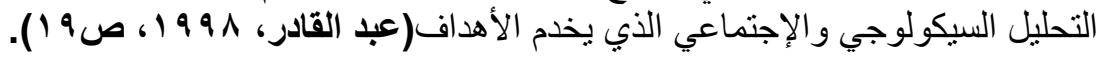

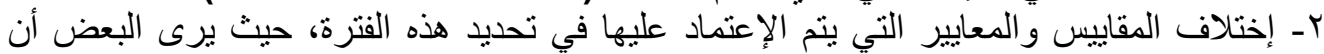

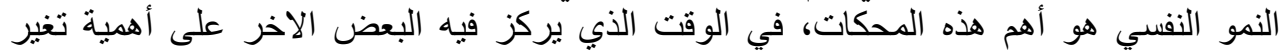

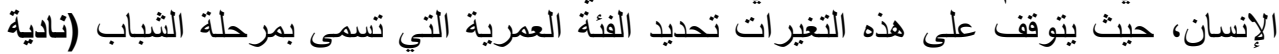

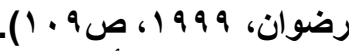

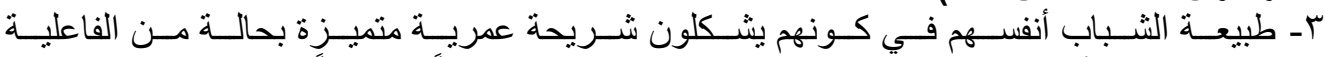

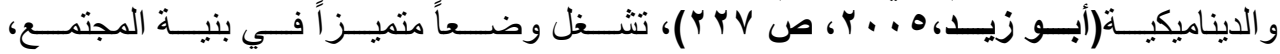

Fayoum J. Agric. Res. \& Dev., Vol. 30, No.2, July, 2016 
$9 \varepsilon$

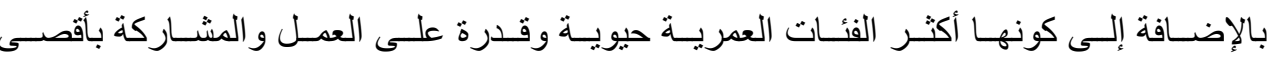

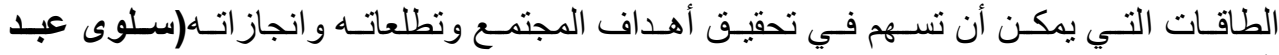

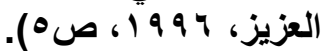

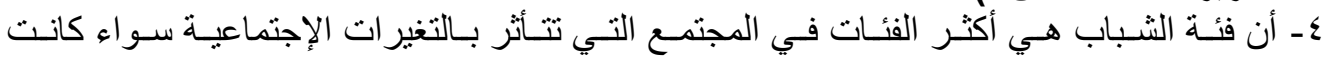

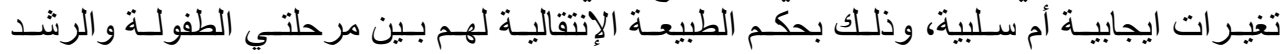

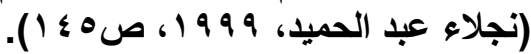

أهمية تقديم الخدمة الإرشادية للشباب الرئ الريفي:

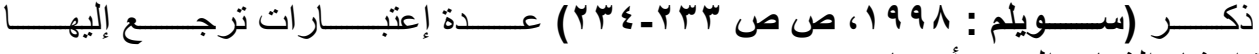

أهمية إرشاد الثباب الريفى أهمها:

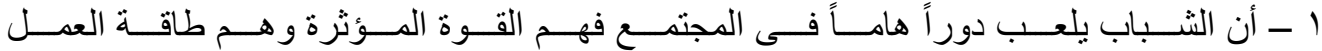

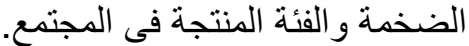

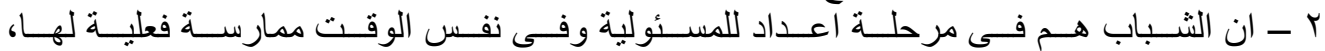

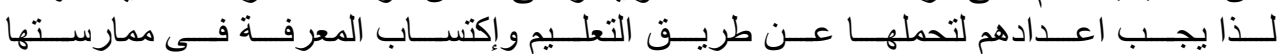
عن طريق العمل و المشاركة الاجتماعية.

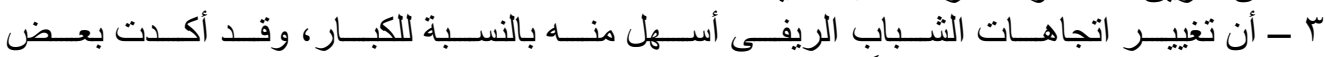

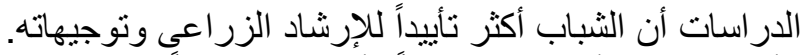

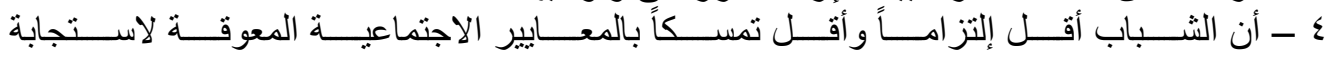

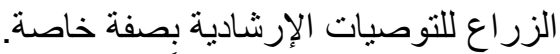

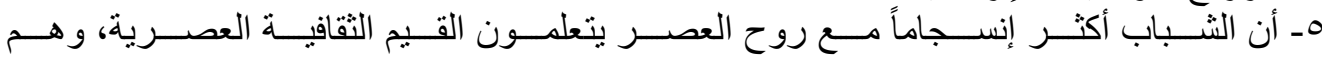

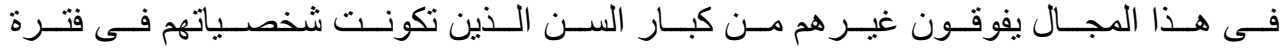
مبكرة من حياتهم.

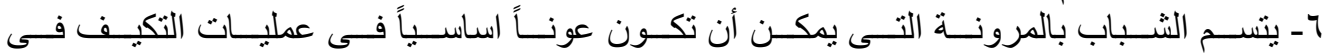
المو اقف التى تو اجه8م.

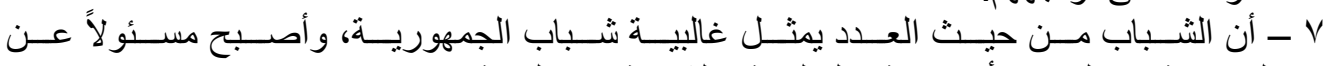

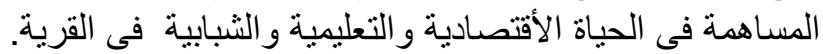

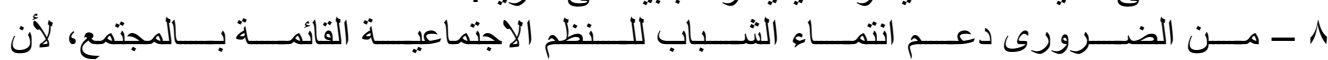

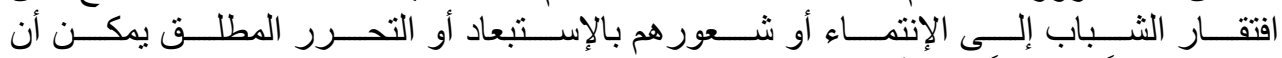

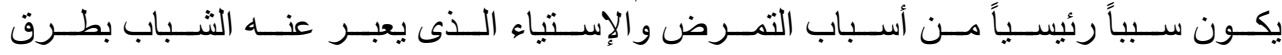
مختلفة عادة ما تكون غير رئ وظيفية.

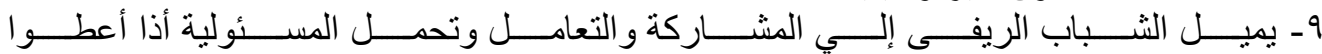
الفرصة المناسبة لذلك.

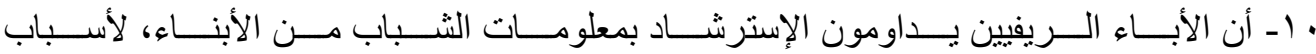

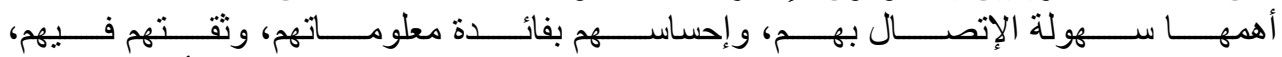

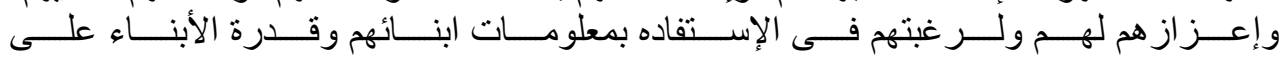
توصبل المعلومات لو الدمبهم.

الطريقة البحثية

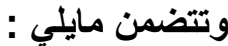

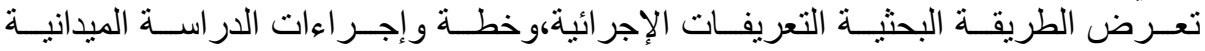

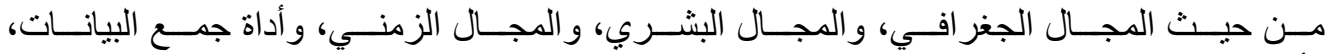
و أدوات التحليل الإحصائي. وفيماً يلي عرض الجن تلك النقاط:

Fayoum J. Agric. Res. \& Dev., Vol. 30, No.2, July, 2016 


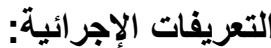

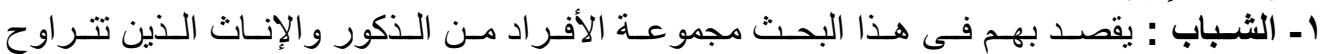

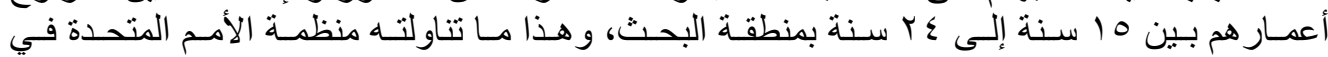

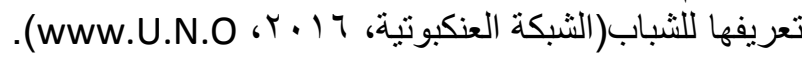

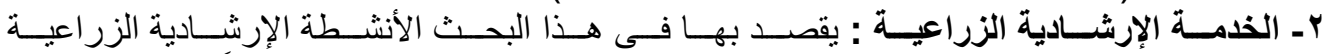

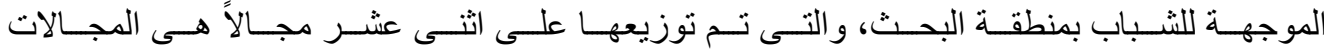

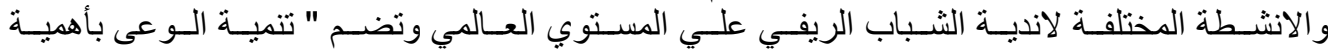

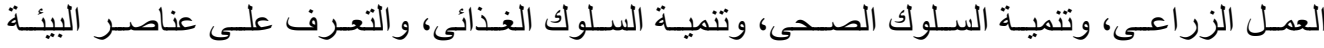

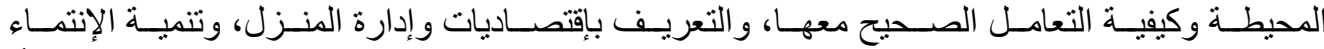

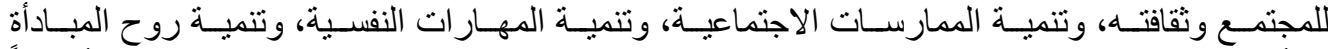

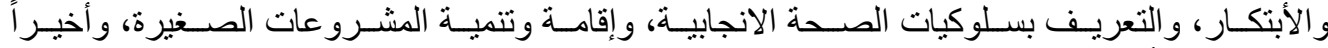
تثنية الوعي بأهم المشكلات المحلية و العالمية".

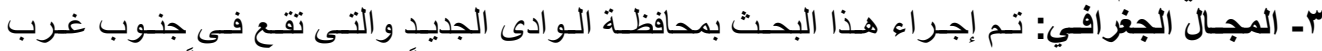

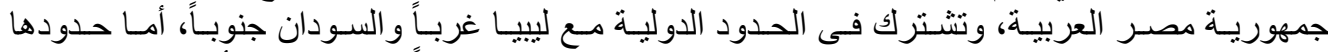

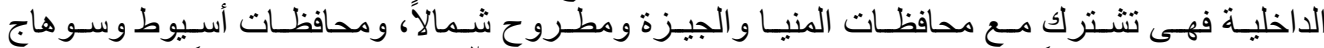

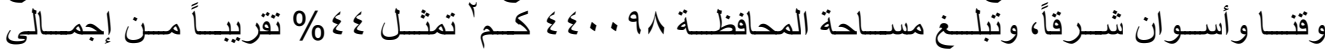

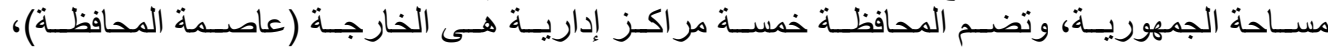

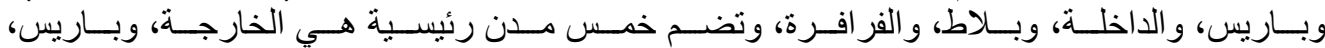

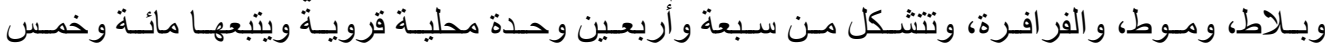

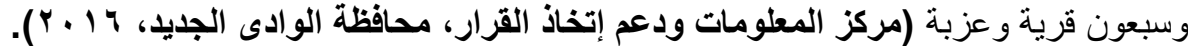

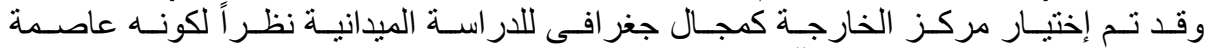

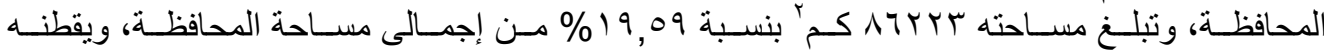

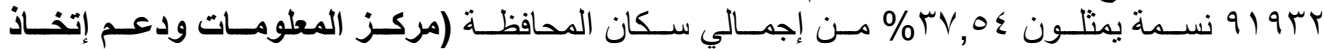

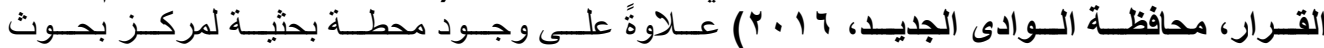

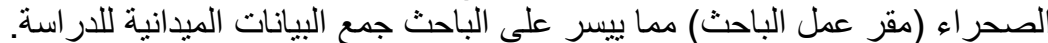

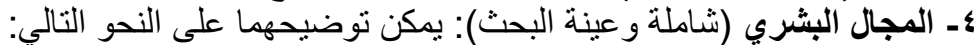

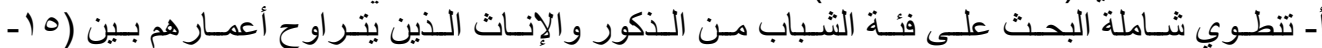

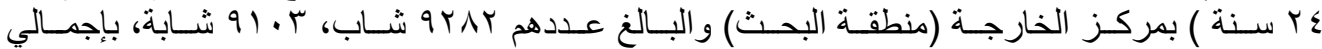

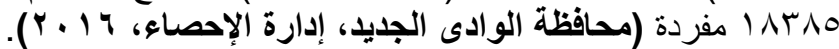

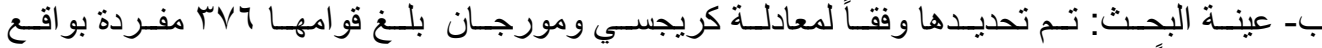

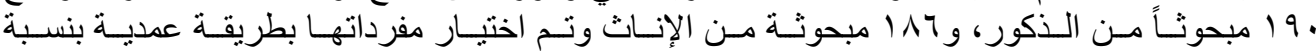

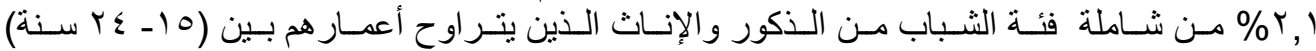
وبما بنطبق عليهم شرط السن بمركز الخارجة (منطقة البحث).

(Krejcie and Morgan 1970:pp, 607-608)

جدول رقم (1) : توزيع شاملة وعينة البحث

\begin{tabular}{|c|c|c|c|c|}
\hline \multicolumn{2}{|c|}{ العينة } & \multicolumn{2}{|c|}{ الشاملة } & \multirow{2}{*}{ النوع } \\
\hline$\%$ & عدد" & $\%$ & عدد" & \\
\hline 0.0 & 19. & 0.0 & QYAY & ذكور \\
\hline$\leqslant 9,0$ & 1117 & $\leqslant 9,0$ & 91.4 & إناث \\
\hline $1 \cdots$, & TVT & $1 \cdots$, & $1 \wedge r \wedge 0$ & الإجمالى \\
\hline
\end{tabular}

Fayoum J. Agric. Res. \& Dev., Vol. 30, No.2, July, 2016 
97

* جمعت وحسبت من واقع بيانات محافظة الوادي الجديد، إدارة الإحصاء، توزيع السكان وفقاً للفئات العمرية، بيانات

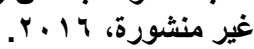

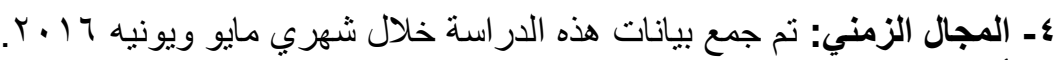

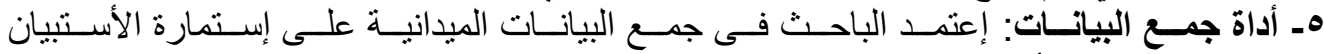

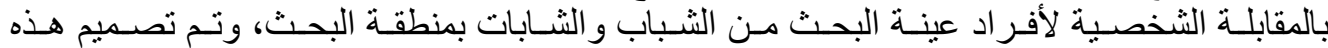

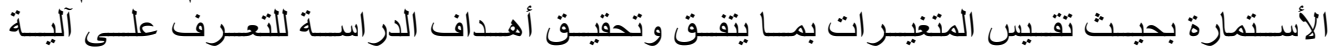

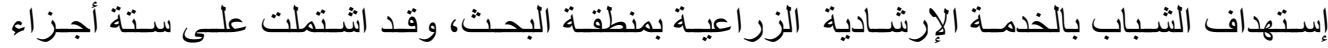

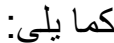

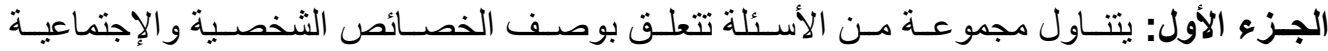

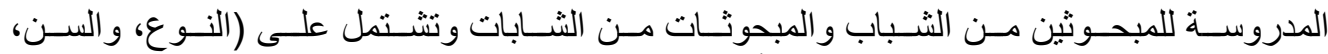

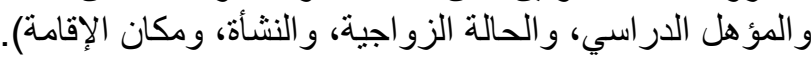

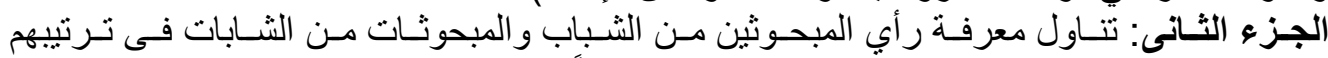

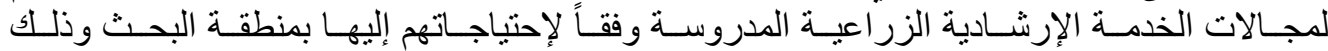

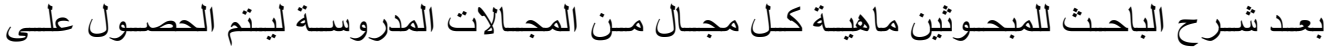

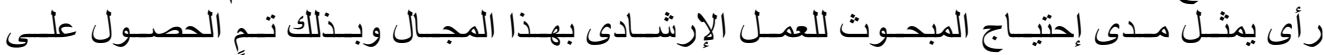

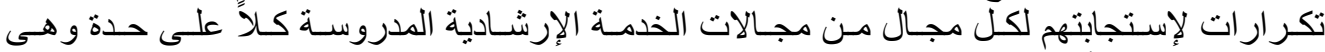

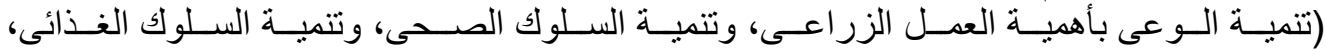

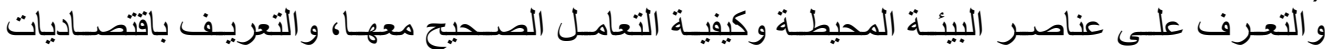

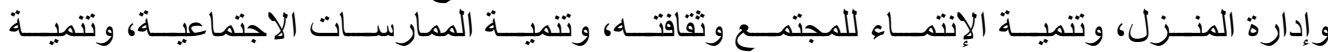

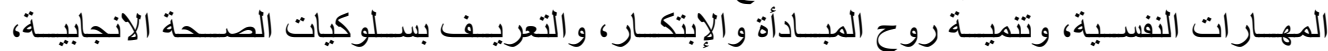

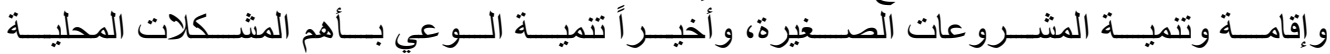
و العالمية).

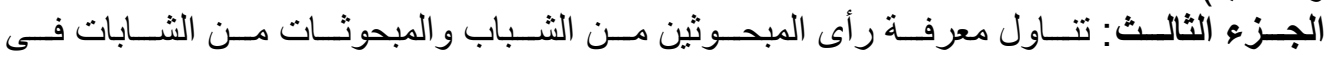

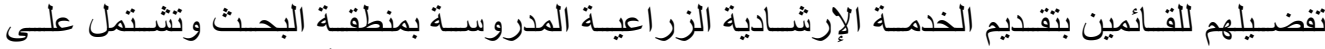

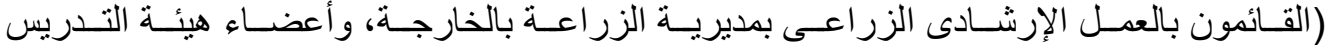

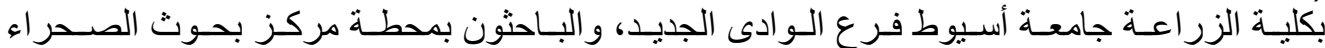

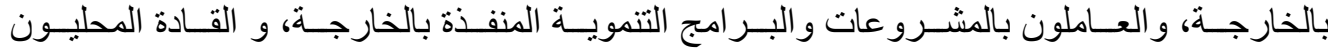

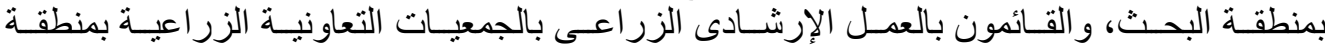
البحن).

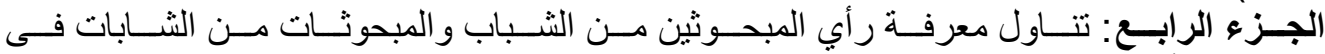

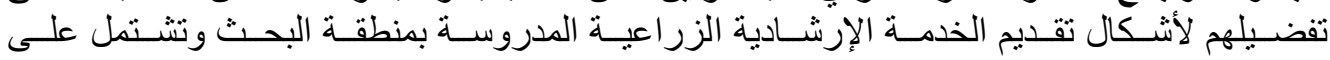

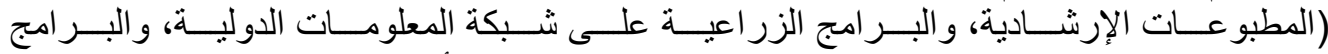

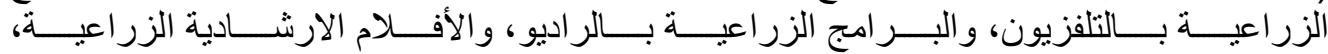

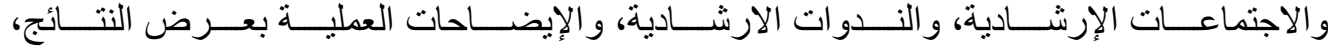

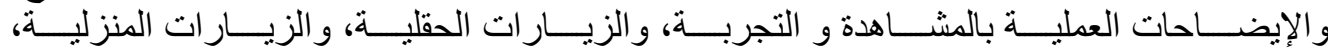

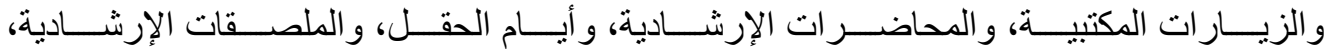

ومكبرات الصوت، والصور الصور الفونو الصر افية).

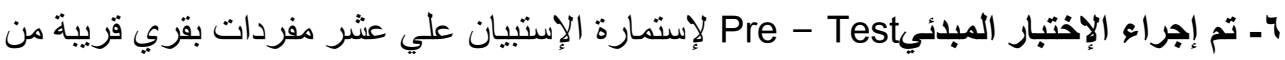
منطقة البحث، و إجر اء التعديلات اللازمة لها حتى أصبحت ملائمة لتحقيق أهداف البحثي.

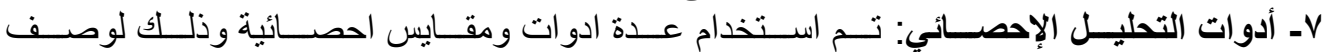

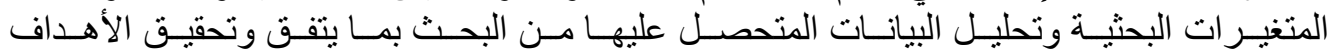
البحثية كما يلى:

Fayoum J. Agric. Res. \& Dev., Vol. 30, No.2, July, 2016 
$9 \vee$

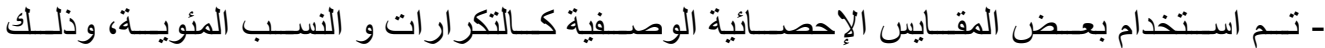

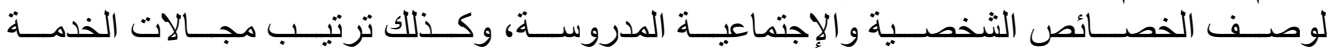

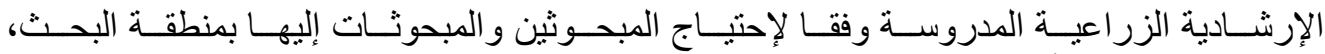

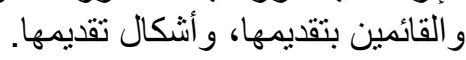

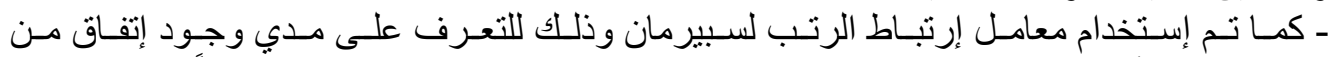

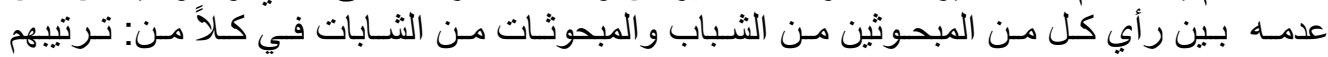

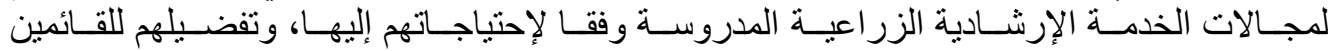

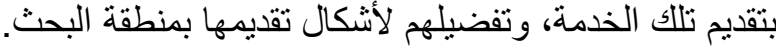

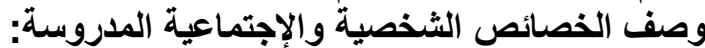

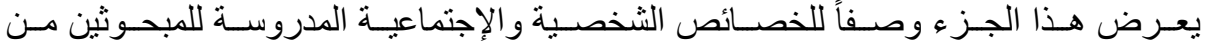

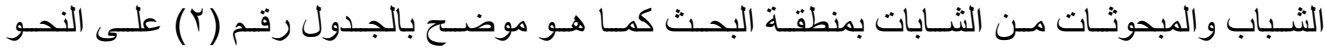

التالى:

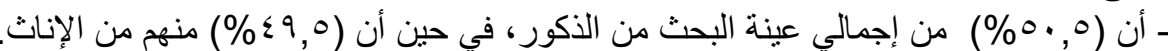

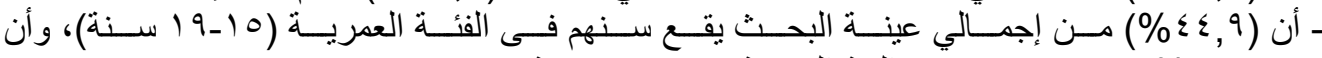

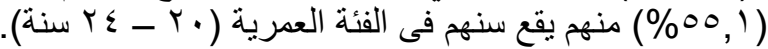

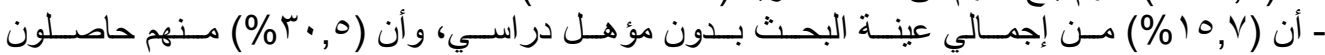

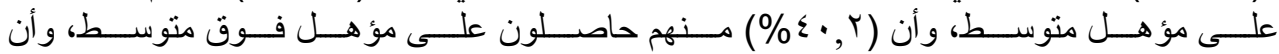

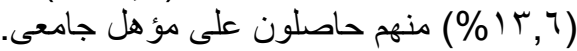

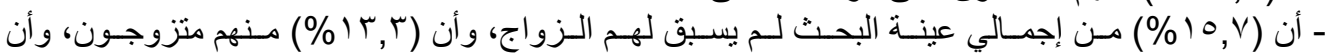

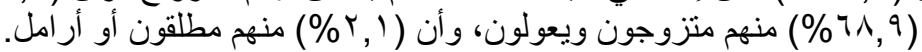

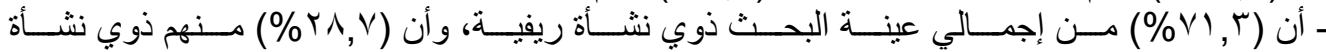

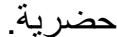

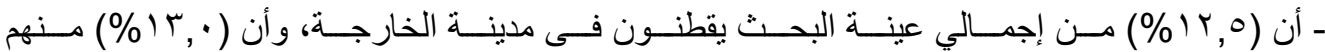

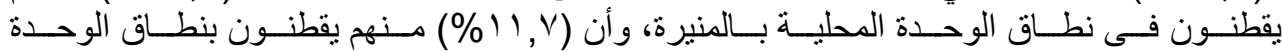

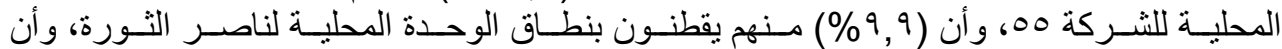

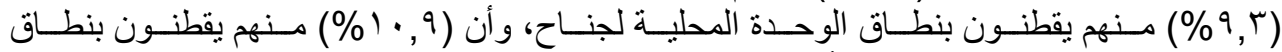

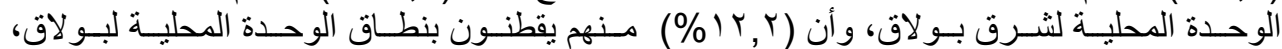

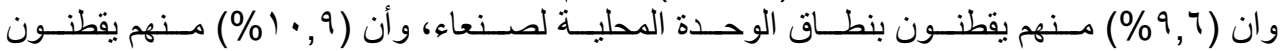
بنطاق الوحدة المحلية لفلسطين.

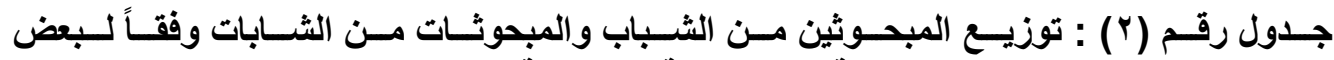

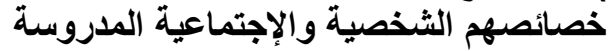

\begin{tabular}{|c|c|c|c|c|c|c|c|}
\hline \multicolumn{2}{|c|}{ الإجمالى } & \multicolumn{2}{|c|}{ المبحوثات من الثـابات } & \multicolumn{2}{|c|}{ المبحوثين من الثباب } & \multirow[b]{2}{*}{ الفئات } & \multirow{2}{*}{ الثخصية الإجتصائة } \\
\hline$\%$ & ن= ع & $\%$ & ن= ع 1 | 1 & $\%$ & ن= •.9 19 & & \\
\hline $0 ., 0$ & 19. & - & - & $1 \cdots$, & 19. & ذكر & \multirow{2}{*}{ النوع } \\
\hline$\varepsilon 9,0$ & 117 & $1 \cdots$, & 1117 & - & - & أنثى & \\
\hline$\varepsilon \varepsilon, 9$ & 179 & $\leqslant 7, \wedge$ & $\Lambda V$ & $\varepsilon r, r$ & Ar & $19-10$ & \multirow{2}{*}{ السن } \\
\hline 00,1 & $T \cdot V$ & $0 r, r$ & 99 & 07,1 & $1 \cdot 1$ & $r \varepsilon-r$. & \\
\hline $10, \mathrm{~V}$ & 09 & $I V, r$ & r & $1 \leqslant, Y$ & rV & بدون مؤهل & المؤهل \\
\hline
\end{tabular}

Fayoum J. Agric. Res. \& Dev., Vol. 30, No.2, July, 2016 
91

\begin{tabular}{|c|c|c|c|c|c|c|c|}
\hline$r \cdot, 0$ & 110 & $r \leqslant, \leqslant$ & $T \varepsilon$ & $r 7,9$ & 01 & مؤهل متوسط & \multirow[t]{3}{*}{ الاراسى } \\
\hline$\varepsilon \cdot, r$ & 101 & $r v, T$ & V. & $\varepsilon r, T$ & NI & مؤهل فوق متوسط & \\
\hline $1 \pi, 7$ & 01 & $1 \cdot, 1$ & $r$. & $17, r$ & r) & مؤهل جامعي & \\
\hline $10, \mathrm{~V}$ & 09 & 11,1 & Tr & 19,0 & rV & أعزب & \multirow{4}{*}{ الزواجية الحالة } \\
\hline $1 \pi, r$ & 0. & $1 \leq$, & rT & Ir,T & $r \varepsilon$ & متزوج & \\
\hline 71,9 & roq & $V Y, T$ & 140 & $70, r$ & ITE & متزوج ويعول & \\
\hline$r, 1$ & $\wedge$ & 1,7 & $r$ & $r, 7$ & 0 & أخرى ( مطلق ، أرمل) & \\
\hline$\overline{v i}, r$ & rTA & $(1,0$ & ITr & $v 1,1$ & 140 & ريفى & \multirow{2}{*}{ النشأة } \\
\hline$r \wedge, \vee$ & $1 \cdot 1$ & $r \Lambda, 0$ & or & $r \wedge, q$ & 00 & حضري & \\
\hline Ir,o & $\sum V$ & 11,1 & TY & $1 r, r$ & ro & مدينة الخارجة & \multirow{9}{*}{ مكان الإقامة } \\
\hline $1 \pi$ & $\leqslant 9$ & $1 \pi, \varepsilon$ & To & $1 r, 7$ & Ts & المنيرة & \\
\hline $11, \mathrm{~V}$ & $\leqslant \varepsilon$ & 11,1 & Tr & 11,7 & TY & الشركة 000 & \\
\hline 9,9 & re & 9,7 & 11 & $1 \cdot, \cdot$ & 19 & ناصر الثوره & \\
\hline $9, r$ & ro & 9,1 & IV & 9,0 & 11 & جناح & \\
\hline $1 \cdot, 9$ & §1 & $1 \cdot, 1$ & $r \cdot$ & 11, & YI & شرق بولاق & \\
\hline$M, r$ & $\leqslant 7$ & Ir, & Tr & $1 r_{1}$ & Tr & بولاق & \\
\hline 9,7 & rq & $1 \cdot, r$ & 19 & 9 & IV & صنعاء & \\
\hline $1 \cdot, 9$ & \&) & $1 \cdot, 1$ & $r$. & 11, & YI & فلسطين & \\
\hline
\end{tabular}

المصدر: نتائج الدراسة الميدانية

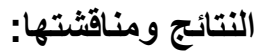

النتائج البحثية ومناقشتئها

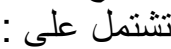

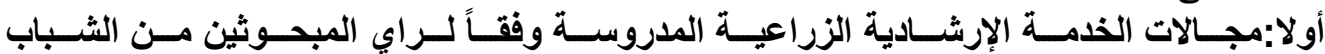
والمبحوثات من الشابات وفقا لاحتياجاتهم اليها بمنطقة البحت البحث:

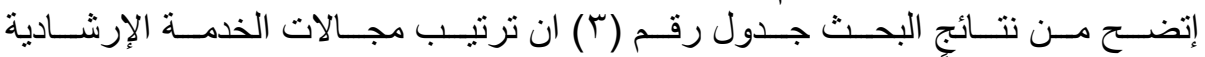

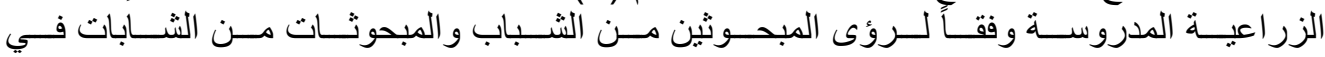

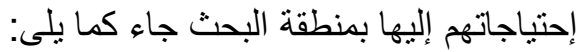

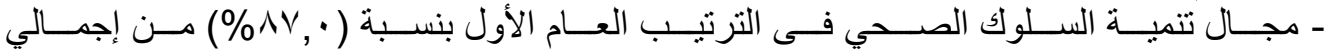

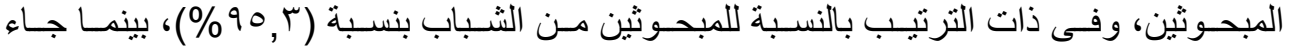

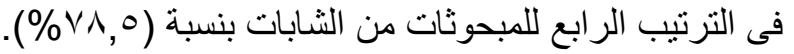

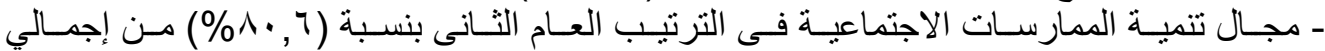

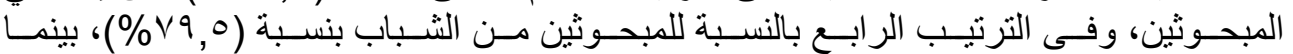

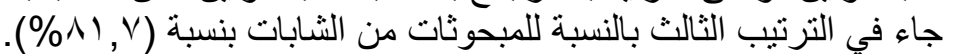

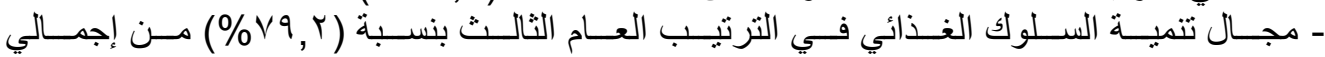

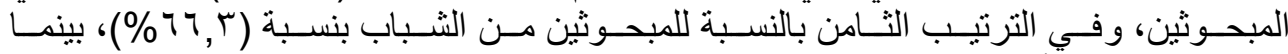

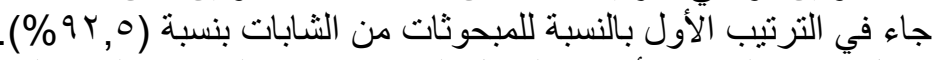

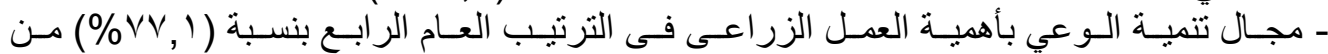

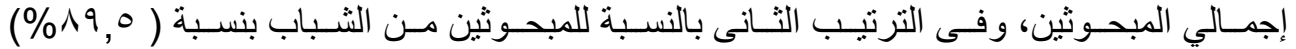

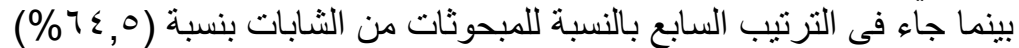

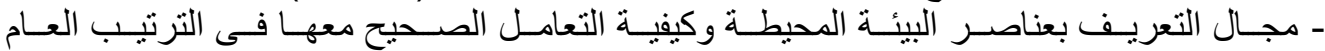

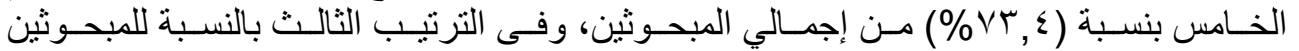

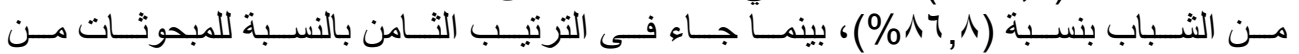

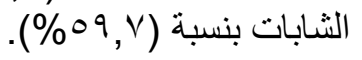

Fayoum J. Agric. Res. \& Dev., Vol. 30, No.2, July, 2016 
99

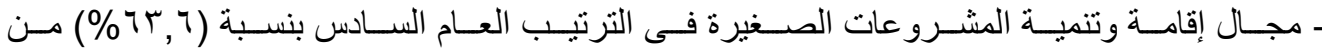

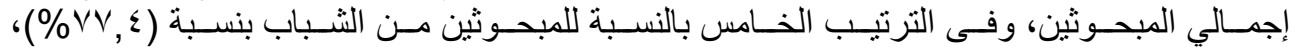
بينما جاء فى الترتيب العاشر بالنسبة للمبحوثات من الثابات بنسبة (

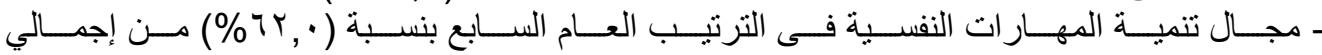

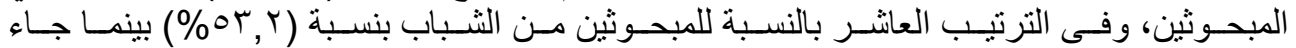

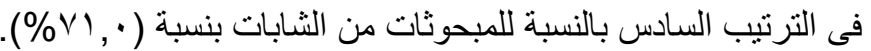

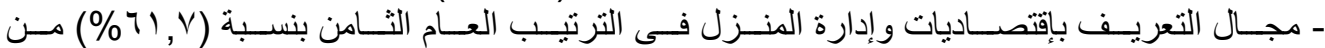

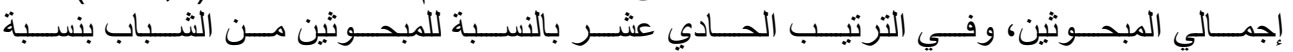
(\%rv, 9)

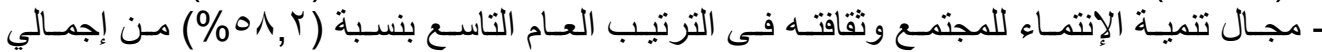

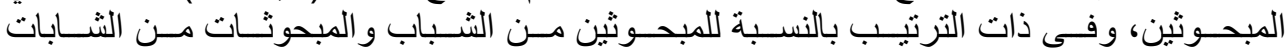

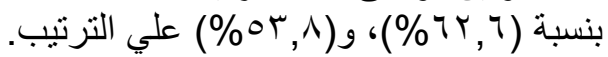

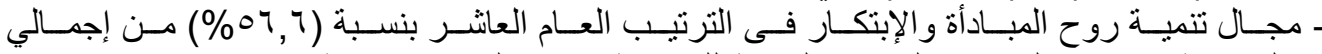

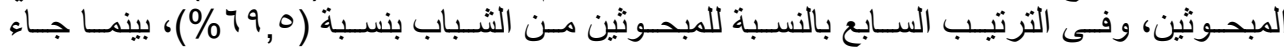

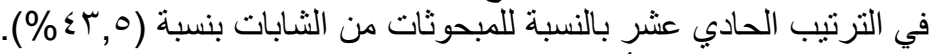

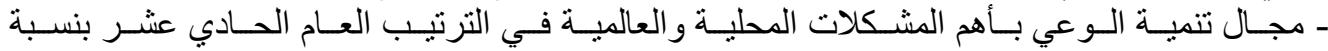

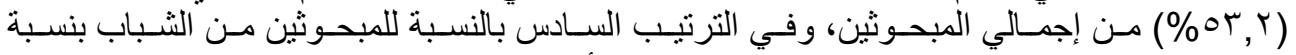

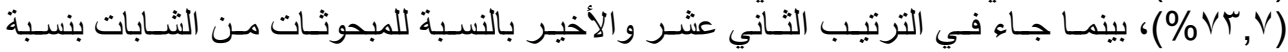
. $(\% r r, r)$

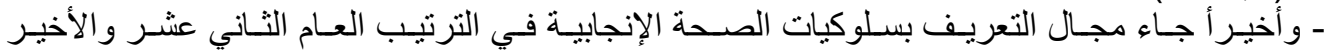

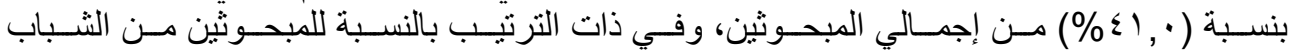

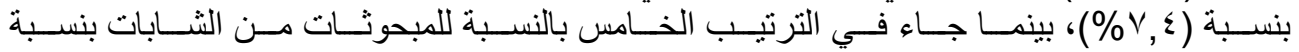

جدول رقم (r): مجالات الخدمة الإرشادية الزراعية المدروسة وفقاً لرأى المبحوثين من الثباب

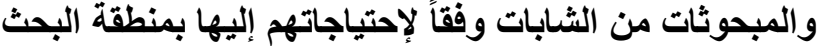

\begin{tabular}{|c|c|c|c|c|c|c|c|c|c|}
\hline \multicolumn{3}{|c|}{ الإجمالى } & \multicolumn{3}{|c|}{ المبحوثات من الثابات } & \multicolumn{3}{|c|}{ المبحوثين من الشباب } & \multirow{2}{*}{ مجالات الخدمة الإرشادية الزراعية البـة بمثية } \\
\hline التعام & $\%$ & نكرار & | الترتيب & $\%$ & نك= تצرار & الترتيب & $\%$ & ن= · · 19 & \\
\hline$\varepsilon$ & $V \vee, 1$ & rq. & V & $7 \leqslant, 0$ & IT. & r & 19,0 & IV. & الوعى بأهمية العمل الزراعي \\
\hline 1 & Av, & TYV & $\varepsilon$ & $\mathrm{VA}, \mathrm{O}$ & $1 \leqslant 7$ & 1 & $90, r$ & 111 & تنمية السلوك الصحي \\
\hline$r$ & $v q, r$ & rq1 & 1 & 94,0 & IVY & $\wedge$ & $77, r$ & $1 \times 7$ & تتمية السلوك الغذائي \\
\hline 0 & $V T, \varepsilon$ & rVT & $\Lambda$ & $09, \mathrm{~V}$ & 111 & $r$ & $\wedge \uparrow, \wedge$ & 170 & التعريف بعناصر البيئة المحيطة \\
\hline$\Lambda$ & $71, \mathrm{~V}$ & rTt & r & $\wedge\urcorner, \cdot$ & 17. & 11 & $r v, q$ & VY & التعريف بإقتصاديات و إدارة المنزل \\
\hline 9 & $0 \wedge, Y$ & r19 & 9 & or, , & $1 \cdots$ & 9 & $7 r, 7$ & 119 & تنمية الإنتماء للمجتمع وثقافته \\
\hline$r$ & $1 \cdot, 7$ & $r \cdot r$ & $r$ & $11, \mathrm{~V}$ & 104 & $\varepsilon$ & $v 9,0$ & 101 & تتمية الممارسات الإجتماعية \\
\hline V & $T, \cdot$ & TrT & 7 & $v 1$, & Irr & 1. & or,, & $1 \cdot 1$ & تتمية المهار ات النفسية \\
\hline 1. & 07,7 & rit & 11 & $\leqslant r, 0$ & 人) & V & 79,0 & ITr & تتمية روح المبادأة والإبتكار \\
\hline IT & $\varepsilon 1$, & $10 \leqslant$ & 0 & $v 0, r$ & $1 \leqslant$ & ir & $\mathrm{V}, \varepsilon$ & $1 \leq$ & التعريف بسلوكيات الصحة الإنجابية \\
\hline 7 & $7 r, 7$ & $r+q$ & 1. & $\leqslant 9,0$ & 94 & 0 & $V \vee, \Sigma$ & $1 \leq V$ & إقامة وتنمية المشرو عات الصغيرة \\
\hline
\end{tabular}

Fayoum J. Agric. Res. \& Dev., Vol. 30, No.2, July, 2016 
1..

\begin{tabular}{|c|c|c|c|c|c|c|c|c|c|}
\hline 11 & or,$r$ & r... & IT & $r$ & 7. & 7 & $V r, v$ & $1 \leq$. & تنمية الوعى بأهم المشكلات المحلية \\
\hline
\end{tabular}

وللتعرف على مدى وجود إتفاق من عدمه بين رأي كل من المبحوثين من الثباب و المبحوثات من الثابات في

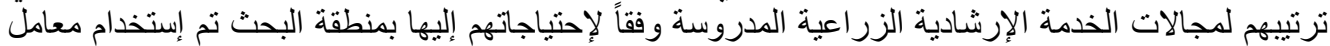

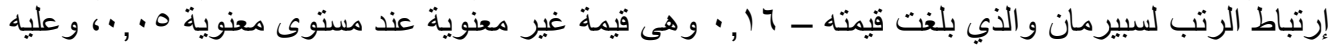

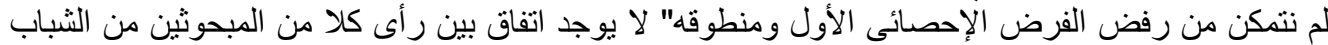

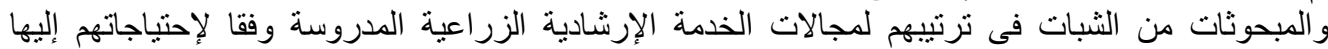
بمنطقة البحث " و عدم قبول الفي الفرض فئ البحثى البديل.

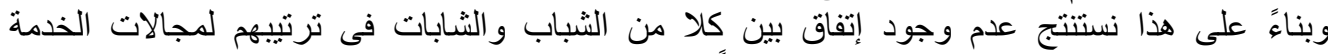

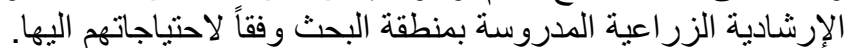

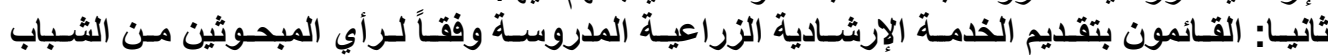

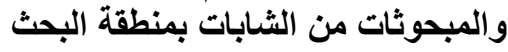

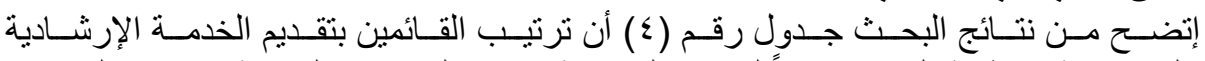

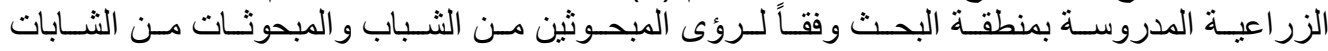

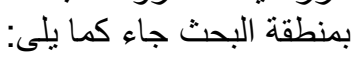

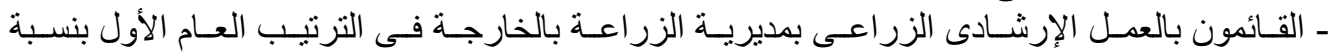

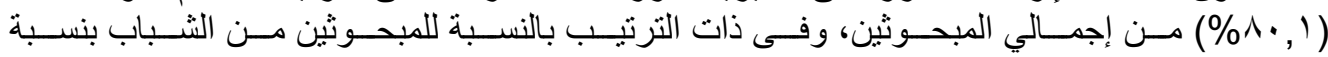

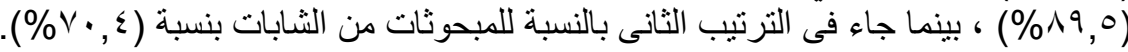

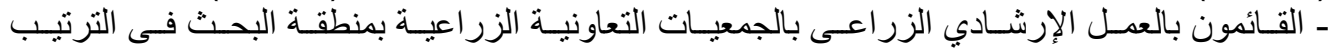

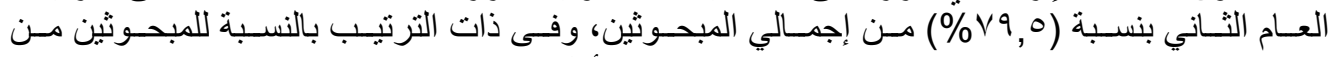

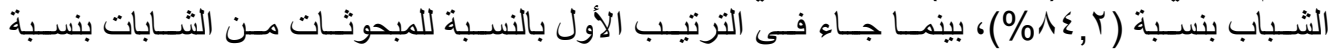
$(\% \vee \varepsilon, \vee)$

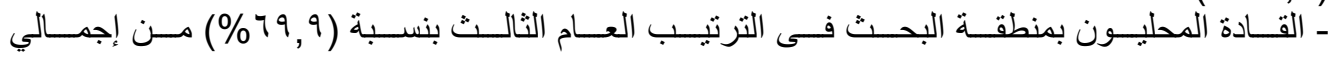

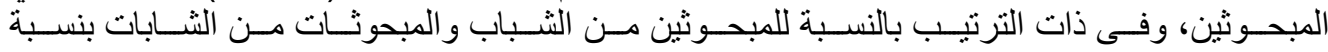

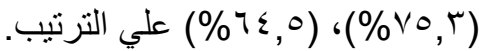

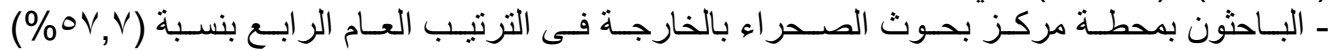

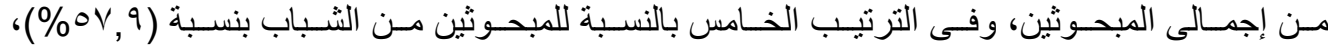

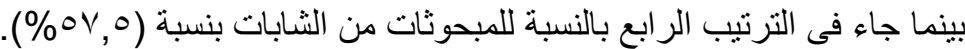

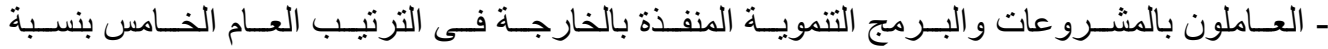

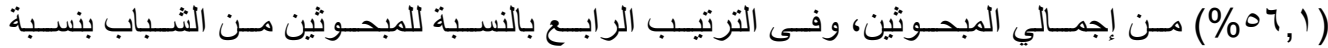

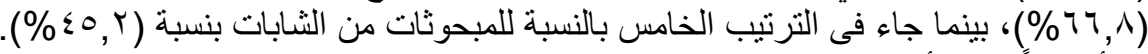

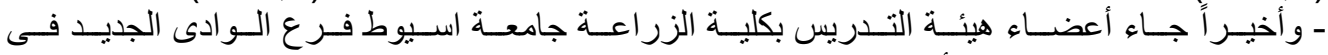

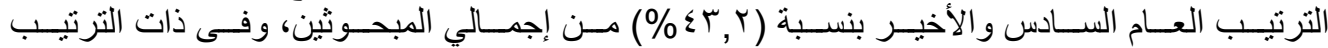

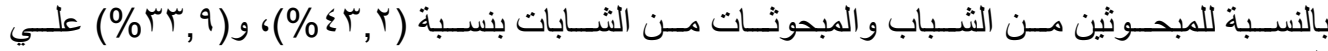
الترثيب. جدول رقم (ع) ): ترتيب القائمين بتقديم الخدمة الإرشادية الزراعية المدروسة وفقاً لرأي المبحوثين من

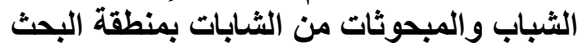

\begin{tabular}{|c|c|c|c|c|c|c|c|c|c|}
\hline \multicolumn{3}{|c|}{ الإجمالى } & \multicolumn{3}{|c|}{ المبحوثات من الثابات } & \multicolumn{3}{|c|}{ المبحوثين من الثباب } & \multirow{2}{*}{ الزراعية المدروسة بتمنيمة الخدمة الإرشادية البحث } \\
\hline 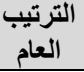 & $\%$ & ن تكرار & الترتيب & $\%$ & ن ت تكرار & الترتيب & $\%$ & ن= • • & \\
\hline 1 & $\wedge \cdot, 1$ & $r \cdot 1$ & r & $v \cdot, \varepsilon$ & $1 \pi$ & 1 & 19,0 & iv. & يرية الزر الاعة بالخادي الزرة اعي \\
\hline 7 & $r \wedge, 7$ & $1 \leqslant 0$ & 7 & r & ז4 & 1 & $\varepsilon r, r$ & Nr & 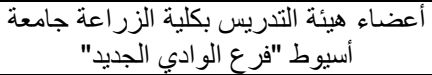 \\
\hline$\varepsilon$ & $O V, Y$ & YIV & $\varepsilon$ & ov, o & $1 \cdot v$ & 0 & ov, 9 & 11 . & الباحثون بمحطة مركز بحوث الصحر اء \\
\hline
\end{tabular}

Fayoum J. Agric. Res. \& Dev., Vol. 30, No.2, July, 2016 
$1 \cdot 1$

\begin{tabular}{|c|c|c|c|c|c|c|c|c|c|}
\hline & & & & & & & & & بالخارجة \\
\hline 0 & 07,1 & YII & 0 & $\varepsilon 0, r$ & $\wedge \varepsilon$ & $\varepsilon$ & $77, \wedge$ & IYV & العاملون بالمشرفة عالخارجة البرامج التنموية \\
\hline$r$ & 79,9 & TIT & $r$ & $T \leqslant, 0$ & $\pi$. & $r$ & Vo,r & $1 \leqslant r$ & القادة المحليين بمنطقة البحث \\
\hline$r$ & $\vee 9,0$ & rq৭ & 1 & $V \varepsilon, V$ & 149 & r & $\Lambda \varepsilon, r$ & 17. & بالجمعيات التعاونية الزر العية بمنطقة الزئي \\
\hline
\end{tabular}

المصدر: نتائج الاراسة الميدانية

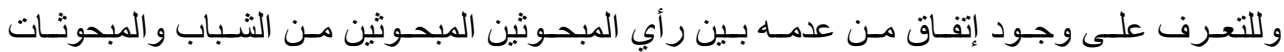

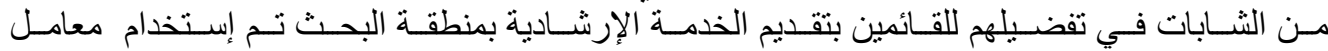

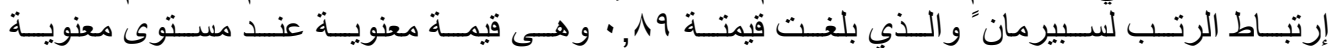

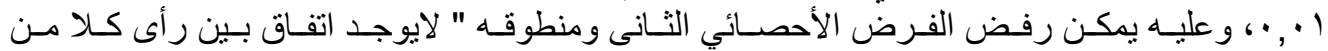

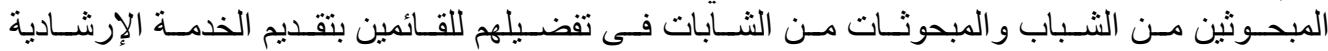

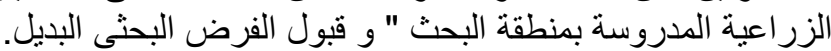

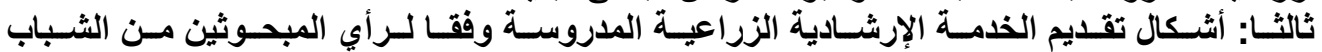
و المبحوثات من الثشابات في تفضيلهم لها بمنطقة الثية البحث:

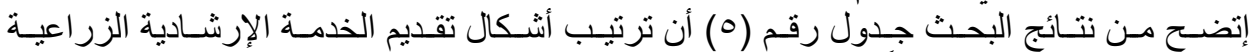

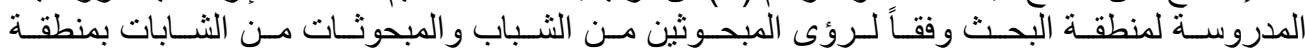

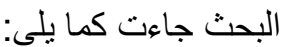

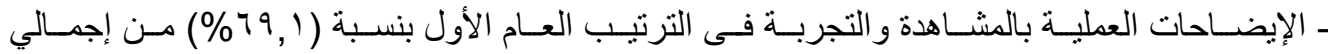

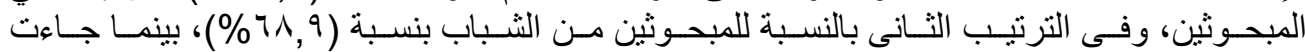

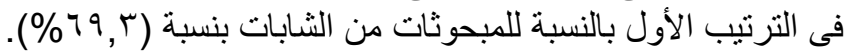

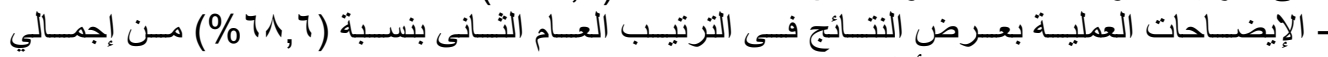

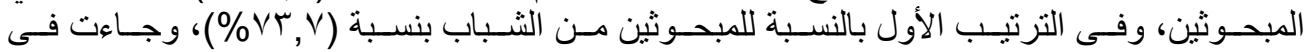

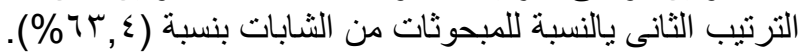

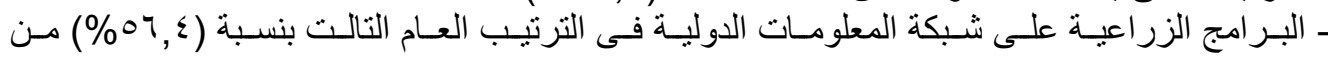

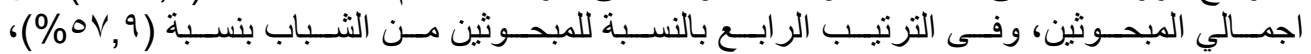

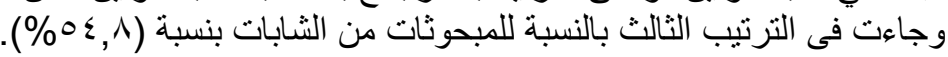

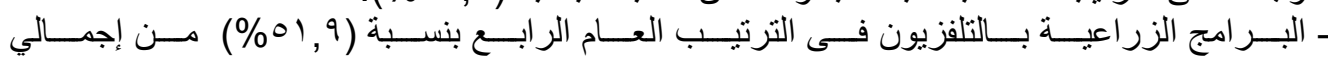

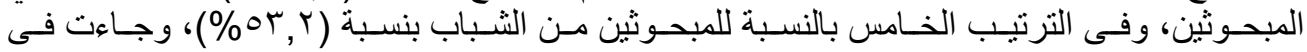

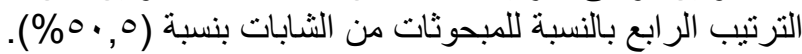

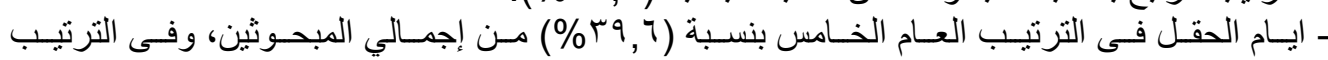

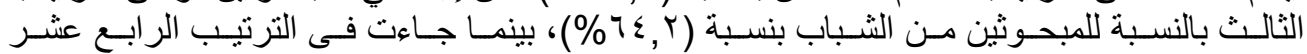

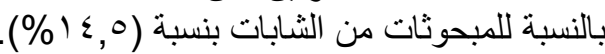

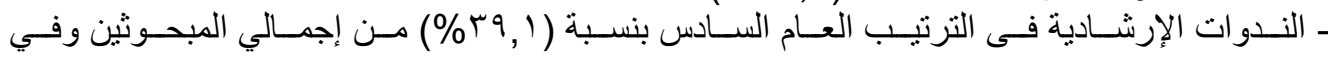

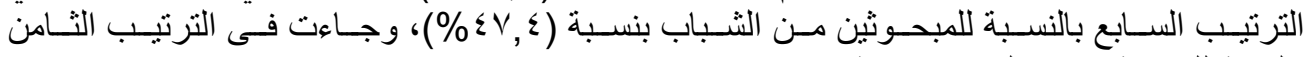

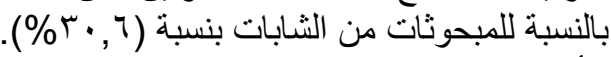

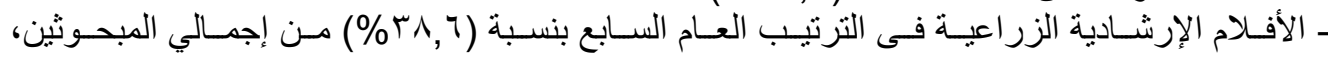

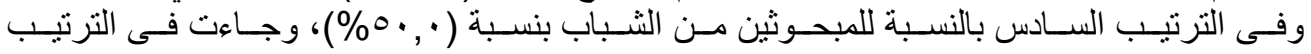

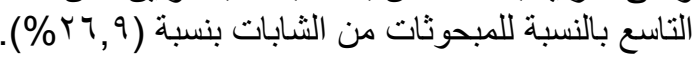

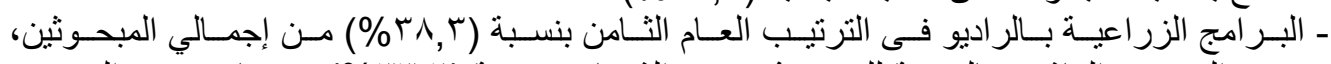

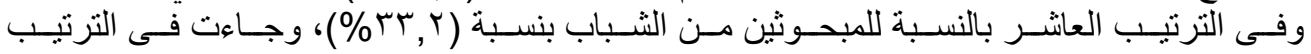

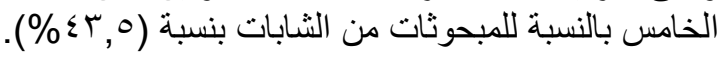

Fayoum J. Agric. Res. \& Dev., Vol. 30, No.2, July, 2016 
$1 \cdot r$

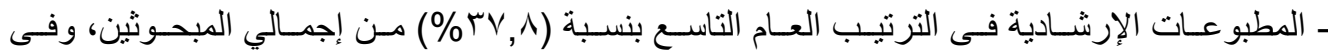

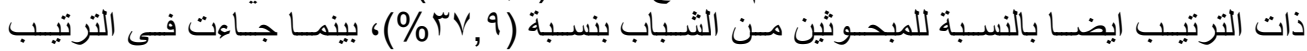

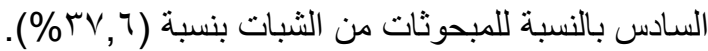

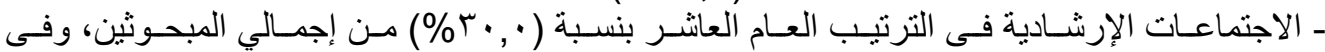

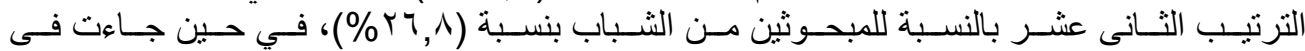

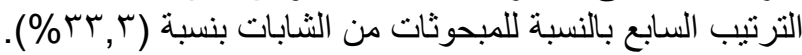

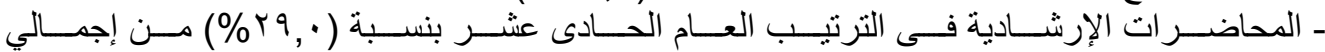

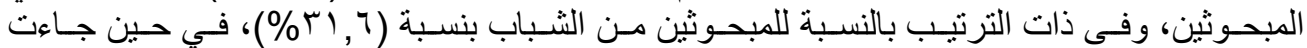

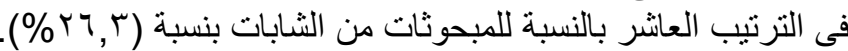

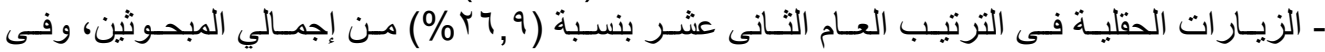

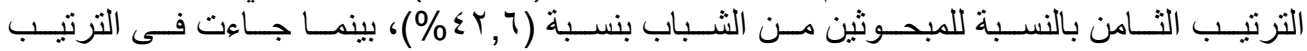

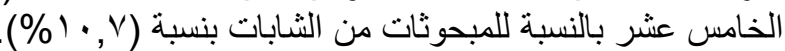

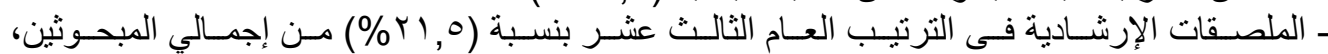

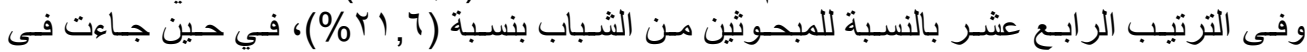

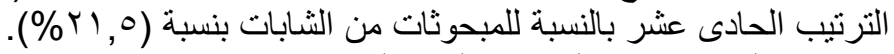

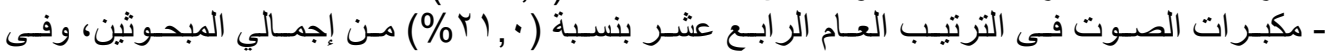

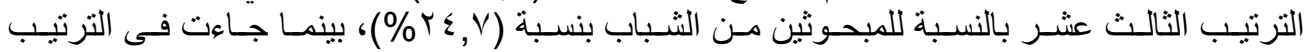

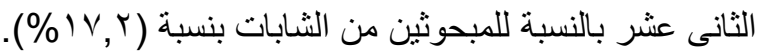

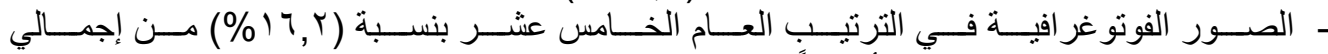

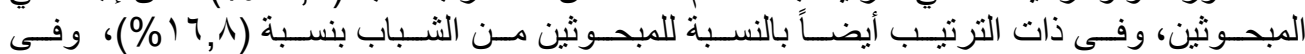

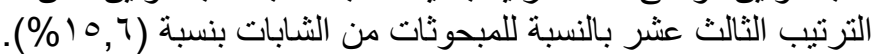

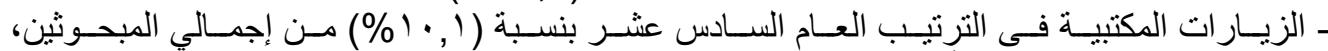

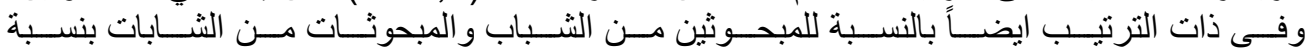

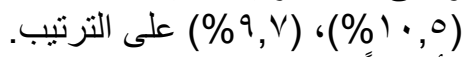

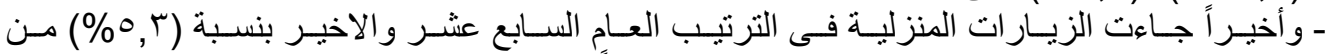

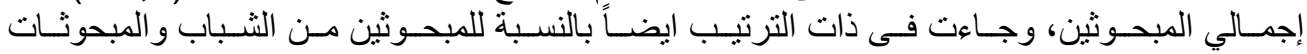

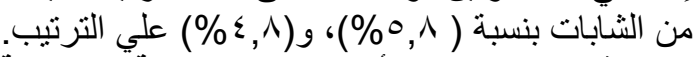
جدول رقم (ه) : ترثيب أثكال تقديم الخدمة الإرشادية الثرثبة الزراعية المدروسة وفقاً لرأي المبحوثين من

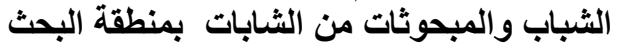

\begin{tabular}{|c|c|c|c|c|c|c|c|c|c|}
\hline \multicolumn{3}{|c|}{ الإجمالى } & \multicolumn{3}{|c|}{ المبحوثات من الثابات } & \multicolumn{3}{|c|}{ المبحوثين من الشباب } & \multirow{2}{*}{ الزراعية المدروسة تقدمة الخطقة الإشادية البحث } \\
\hline الترتيب & $\%$ & ن تكرار & الترتيب & $\%$ & ن تكرار & الترتيب & $\%$ & ن= تكرار & \\
\hline 9 & $r v, \wedge$ & $1 \leqslant r$ & 7 & $r v, 7$ & $v \cdot$ & 9 & $r v, q$ & $V Y$ & المطبو عات الإرشادية \\
\hline r & $07, \varepsilon$ & rit & $r$ & $0 \leqslant, \wedge$ & $1 \cdot r$ & $\varepsilon$ & ov, 9 & 11. & المعلومات الزراعية الدية على شبكة \\
\hline$\varepsilon$ & 01,9 & 190 & $\varepsilon$ & $0 ., 0$ & $9 \leq$ & 0 & or, $r$ & $1 \cdot 1$ & البر امج الزر اعية بالتليفزيون \\
\hline$\wedge$ & $r \wedge, r$ & $1 \leq \varepsilon$ & 0 & $\varepsilon r, 0$ & $\wedge$ & 1. & r & $\pi$ & البر امج الزر اعية بالر اديو \\
\hline V & $r \wedge, 7$ & $1 \leqslant 0$ & 9 & $r 7, q$ & 0. & 7 & $0 \cdot, \cdot$ & 90 & الافلام الإرشادية الزر اعية \\
\hline $1 \cdot$ & $r \cdot, \cdot$ & $11 \pi$ & V & (r & Tr & ir & $r \uparrow, \wedge$ & 01 & الإجتماعات الإرشادية \\
\hline 7 & $r q, 1$ & $1 \leqslant V$ & $\wedge$ & $r \cdot, T$ & ov & v & $\varepsilon v, \varepsilon$ & 9 . & الندوات الإرشادية \\
\hline r & $7 \wedge, 7$ & roN & r & $\pi$ & 111 & 1 & vr, & $1 \leq$ & الإيضاحات العملية بعرض النتائج \\
\hline 1 & 79,1 & YT. & 1 & $79, r$ & 149 & r & $7 \wedge, 9$ & $|r|$ & لإِيضاحات العملية بالمشاهدة والتجربة \\
\hline ir & $r 7,9$ & $1 \cdot 1$ & 10 & $1 \cdot, \mathrm{V}$ & $r \cdot$ & $\Lambda$ & $\varepsilon r, T$ & $\Lambda 1$ & الزيار ات الحقلية \\
\hline IV & $0, r$ & $r \cdot$ & IV & $\varepsilon, \wedge$ & 9 & IV & 0,1 & 11 & الزيار ات المنزلية \\
\hline
\end{tabular}

Fayoum J. Agric. Res. \& Dev., Vol. 30, No.2, July, 2016 


\begin{tabular}{|c|c|c|c|c|c|c|c|c|c|}
\hline 17 & $1 \cdot, 1$ & $\Gamma_{\Lambda}$ & 17 & $9, \mathrm{~V}$ & 11 & 17 & $1 \cdot, 0$ & $r$. & الزيارات المكتبية \\
\hline 11 & $r q$, & 1.9 & 1. & $r+r$ & $\leqslant 9$ & 11 & $r, 7$ & 7. & المحاضر ات الإرشـادية \\
\hline 0 & $r q, 7$ & $1 \leq 9$ & $1 \varepsilon$ & $1 \leqslant, 0$ & TV & $r$ & $T \varepsilon, r$ & ITY & أيام الحقل \\
\hline 14 & $r 1,0$ & \I & 11 & $r 1,0$ & $\varepsilon \cdot$ & $1 \varepsilon$ & $r, 7$ & \&1 & الملصقات الإرشادية \\
\hline $1 \varepsilon$ & ri, & 19 & ir & $I V, Y$ & r & ir & $r \leqslant, V$ & $\varepsilon V$ & مكبر ات الصوت \\
\hline 10 & $17, r$ & 71 & Tr & 10,7 & rq & 10 & $17, \wedge$ & Tr & الصور الفوتو غرفية \\
\hline
\end{tabular}

المصدر: نتائج الاراسة الميدانية

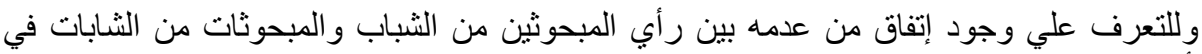

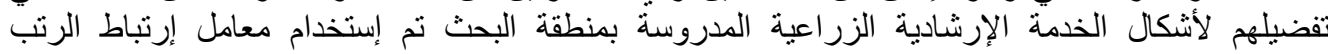

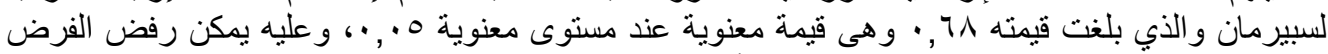

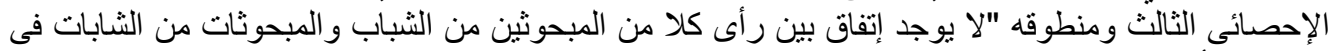

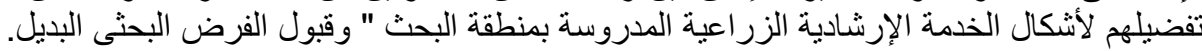

التوصيات

بناءً علي النتائج البحثية يمكن التوصية بما يلي : الرئية

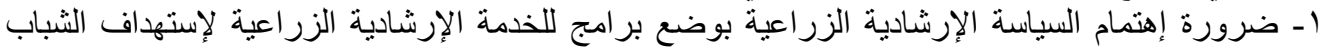

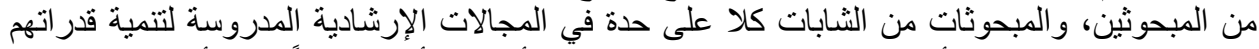

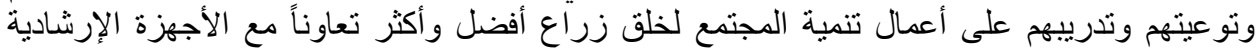

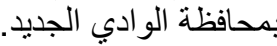

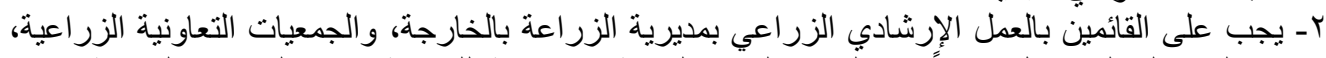

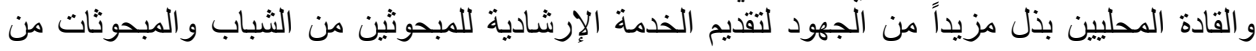

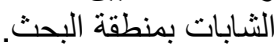

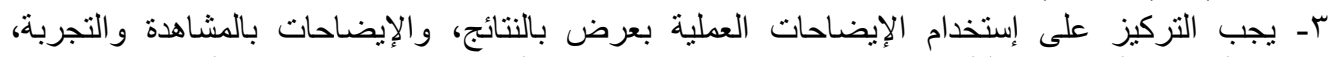

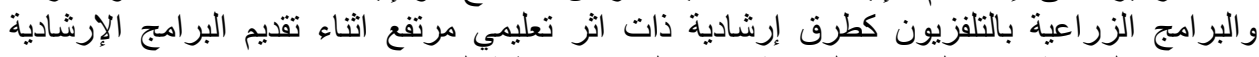

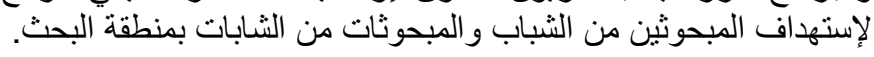

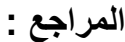

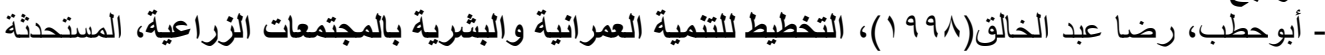

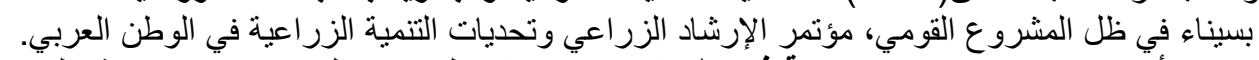

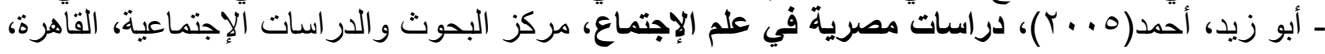

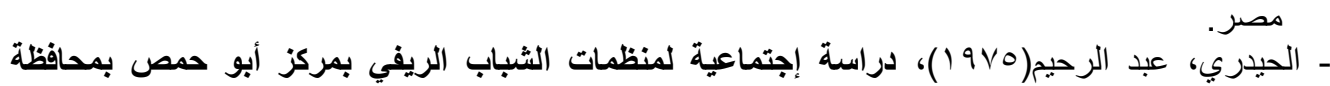

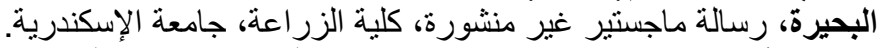

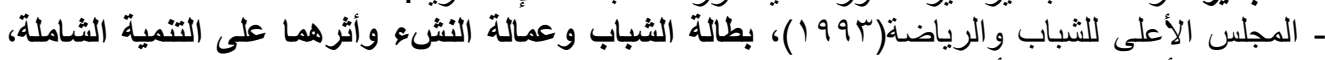

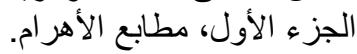

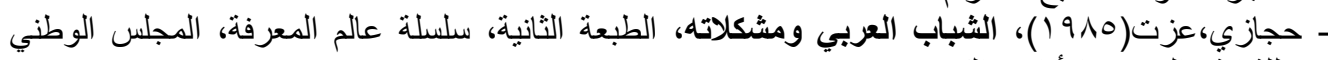

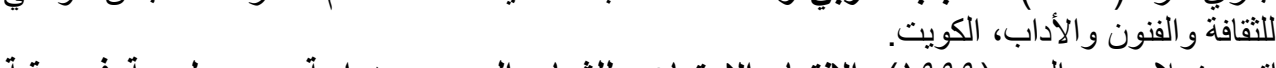

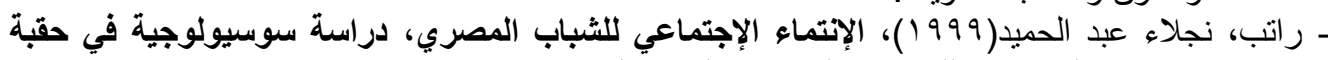

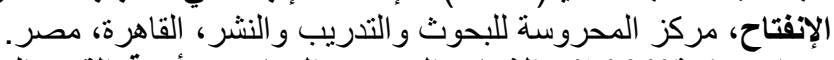

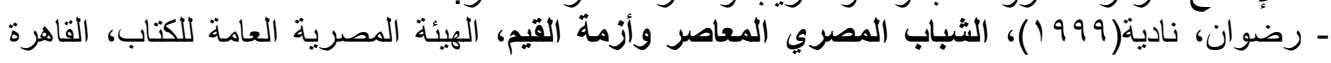
مصر. - سليمان، عدلي(970 (19)، الثباب ومجتمعنا الإشتراكي، دار النهضة، القاهرة، مصر.

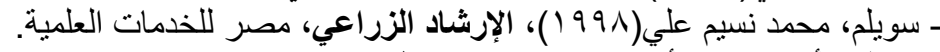

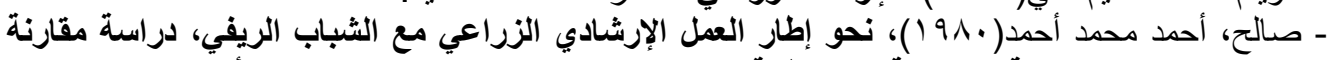

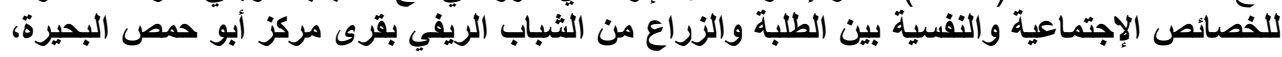

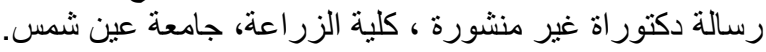

Fayoum J. Agric. Res. \& Dev., Vol. 30, No.2, July, 2016 


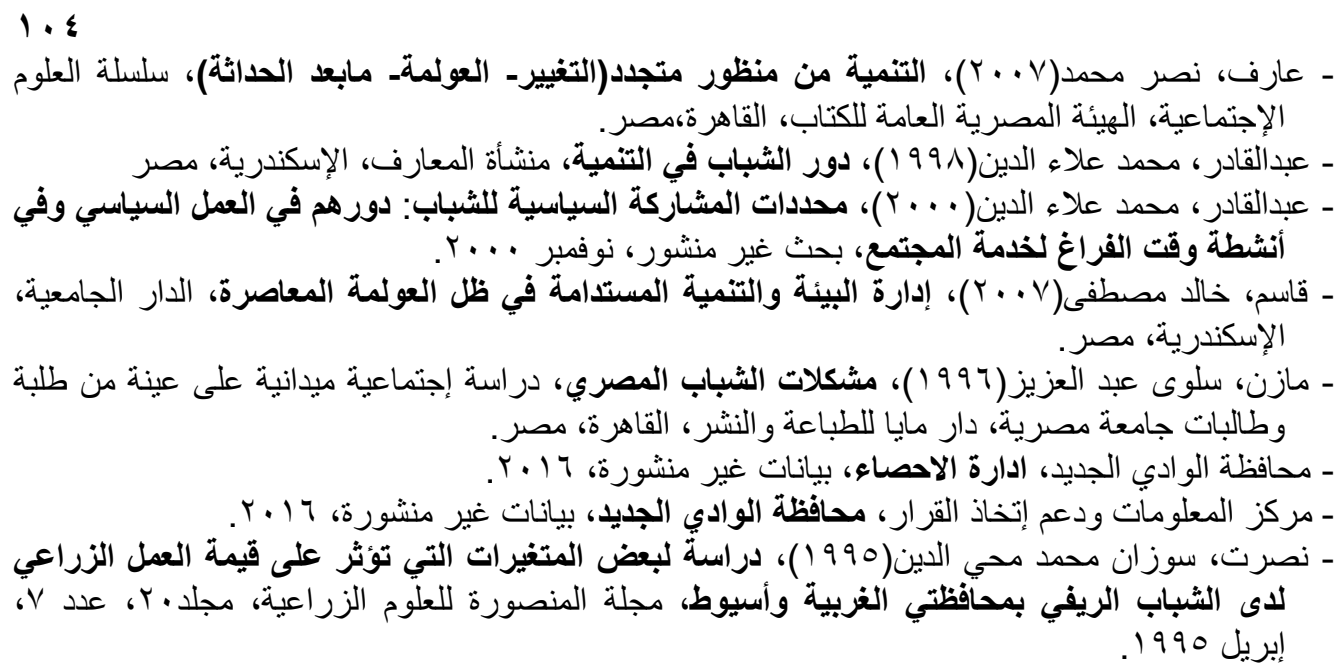

- Krejcie , R .V and Morgan , D.W : Determining sample size for reasearch activities eductional and psychological measurement, college station Urham, north Carolina, 1970.

- WWW. United Nations Organzition / esa/ soclev/ documents/Youth/ factsheets/Youth- definition Pdf.

\section{TARGETING YOUTH AGRICULTURAL EXTENSION SERVICE IN NEW VALLEY GOVERNORATE}

ABSTRACT

Dr. Hossam El Deen Ibrahim Ahmed Abd El Aal

Targeted this research to identify the opinion of respondents from the youth and the respondents of young women in their order to the areas of agricultural extension service studied according to their needs the area search, as well as to identify the opinion of respondents from the youth and the respondents of young women in preference for those in charge to provide agricultural extension service studied area of research, and finally to identify the respondents' opinion of young men and young women of the respondents in the form of preference for the provision of agricultural extension service studied in research region.

This research was conducted on a sample of respondents from the youth and the respondents of young women have been identified, according to the equation Krejse and Morgan stood strong 376 single rate of 190 female and 186 Researched by females were selected vocabulary intentional manner by $2.1 \%$ from a comprehensive youth male The females, which they apply to people who ranged in age from (15-24 years) emerging center (the search area) and 9282 's a young man, and a total of 9103 young 18385 Single.

It was a questionnaire to collect personal data against design during the months of May and June 2016, it has been used several tools and Mqais Kaltkarat statistics and percentages, was also used for the Spearman rank correlation coefficient.

This can be illustrated most important results are as follows:

With respect to the opinion of the respondents from the youth and the respondents of young women in their order to the areas of agricultural extension service studied according to their needs them in research in: the field of the development of healthy behavior came in first place for the respondents from the youth rate $(95.3 \%)$, while came

Fayoum J. Agric. Res. \& Dev., Vol. 30, No.2, July, 2016 
in fourth arrangement for young women (78.5\%), followed by the field of awareness of the importance of agricultural work in the second place for the young respondents rate $(89.5 \%)$, while this area came in the seventh arrangement for young women by $(77.1 \%)$, in while the field of reproductive health behaviors definition came in second ranking tenth and last for respondents from the youth rate $(7.4 \%)$, and in the fifth arrangement for young women by $(75.3 \%)$.

With regard to the opinion of the respondents from the youth and the respondents of young women in preference for those in charge to provide agricultural extension service: came organizers of agricultural work beacon Department of Agriculture Baforeigp in the first ranking for the respondents from the youth rate $(89.5 \%)$ , and in the second place for young women by $(700.4 \%)$, while faculty members came Faculty of Agriculture, Assiut University new valley branch in the sixth and final standings for each of the young men and women in research.

With regard to the opinion of the respondents from the youth at the respondents of young women in their preference for forms provide extension service Search area : The operation clarifications displays the results in the first ranking for the respondents from the youth rate $(73.7 \%)$, and in the second place for young women by $(63.4 \%)$, followed by practical explanations road and experience in the second arrangement for the respondents from the youth rate (68.9\%) and ranking first for young women by $(69.3 \%)$, while home visits came in the seventeenth arrangement and for the last two categories together.

Fayoum J. Agric. Res. \& Dev., Vol. 30, No.2, July, 2016 